\title{
Halonium-Induced Polyene Cyclizations
}

\author{
Agathe C. A. D'Hollander ${ }^{\dagger}$ \\ Laure Peilleron ${ }^{\dagger}$ \\ Tatyana D. Grayfer \\ Kevin Cariou,* \\ Institut de Chimie des Substances Naturelles, CNRS UPR 2301, \\ Univ. Paris-Sud, Univ. Paris-Saclay, 1 Avenue de la Terrasse, \\ 91198 Gif-sur-Yvette, France \\ ${ }^{\dagger}$ These authors contributed equally \\ * Kevin.cariou@cnrs.fr \\ Click here to insert a dedication.
}

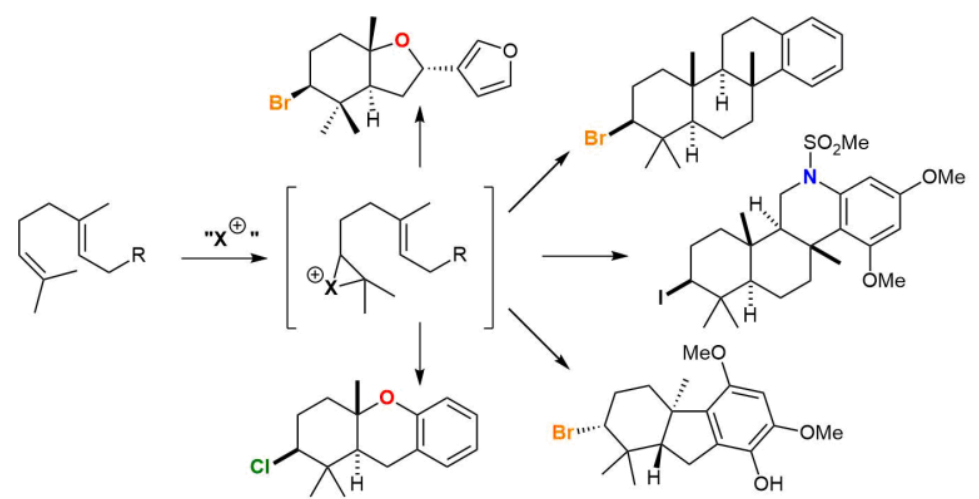

evolved to achieve can raise complex chemo-, regio-, and stereoselectivity issues for the synthetic chemist, especially considering that all patterns could come from a common intermediate.

Abstract This review covers the methods that chemists have developed to access halogenated polycyclic structures from polyenes, by emulating Nature's enzymatic machineries. From pioneering studies to the most recent developments, the different strategies, whether based on the use of standard reagents or on the design of specific ones, will be presented. Finally, asymmetric reactions and applications for the total synthesis of natural products will be exposed.

1 Introduction

$2 \quad$ Pioneering Studies

$3 \quad$ Use of Specific Reagents

4. Use of $\mathrm{N}$-Halo Amides

5. Asymmetric Reactions

6. Total Synthesis of Halogenated Natural Products

7. Conclusion and Perspectives

Key words halogenation, polyenes, biomimetic synthesis, cascade cyclization asymmetric synthesis, natural products.

\section{Introduction}

The intricate polycyclic structures that living organism produce have been a tremendous source of inspiration for chemists, often leading to the development of powerful synthetic methods. From this standpoint, the electrophilic cyclization of polyenes, as pioneered by Stork ${ }^{1}$ and Eschenmoser ${ }^{2}$ in the $50 \mathrm{~s}$, remain a striking example of chemists rivalling Nature in terms of efficiency and selectivity and constitute a landmark for the field of biomimetic synthesis. ${ }^{3}$ Halogenated derivatives ${ }^{4}$ constitute a particular sub-class of polycyclic natural compounds which, because of their complex and original structures and their therapeutic potential, ${ }^{5}$ fueled the development of many synthetic methods. ${ }^{6}$ In Nature the synthesis of these molecules from linear terpenes is achieved through various enzymatic machineries, ${ }^{7}$ that, following initial halogenation of a trisubstituted alkene, can readily achieve halogen-induced carbocyclizations, oxy-halogenations or polyhalogenations. Several of these transformations sometimes occur for the same substrate. For instance, the brominated terpenoid bromophycolide $A,{ }^{8}$ that exhibits three different bromination patterns (including a cyclic one) could basically arise from three distinct electrophilic brominations of a geranylgeranyl starting material (Scheme 1). Yet, what enzymes have

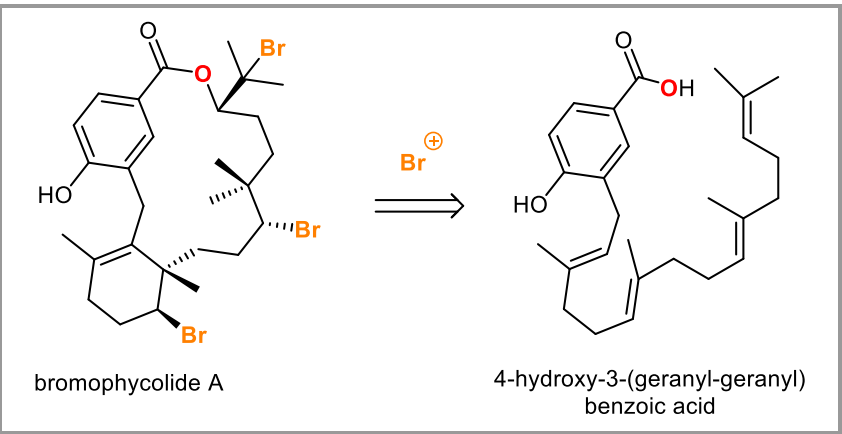

Scheme 1 Schematic biosynthesis of bromophycolide A

Indeed, the first step in the electrophilic bromination of a geranyl derivative $\mathbf{1}$ would lead to a key bridged halonium intermediate 2, which can evolve following different pathways (Scheme 2). Elimination of one $\alpha$-proton would yield allylic halide 3 while nucleophilic opening by an external nucleophile (such as water or a halide) would give disubstituted product 4. Eventually, trapping by the proximal double bond would lead to 6-membered carbocation $\mathbf{5}$ that can then follow various routes such as elimination, trapping or cascade process. This carbocyclization pathway, when not triggered by a suitable enzyme, is generally the most difficult to favor compared to the other two major options.

It is important to note that for the halocyclization of a linear terpene, such as geranyl derivative $\mathbf{1}$, the relative cisconfiguration of the resulting cyclohexyl cation $\mathbf{5}$ is dictated by the configuration of the bridged halonium $\mathbf{2}$ since the cyclization would take place through an $\mathrm{S}_{\mathrm{N}} 2$-type mechanism on a preorganized (most often chair-like) transition state (Scheme 3). 


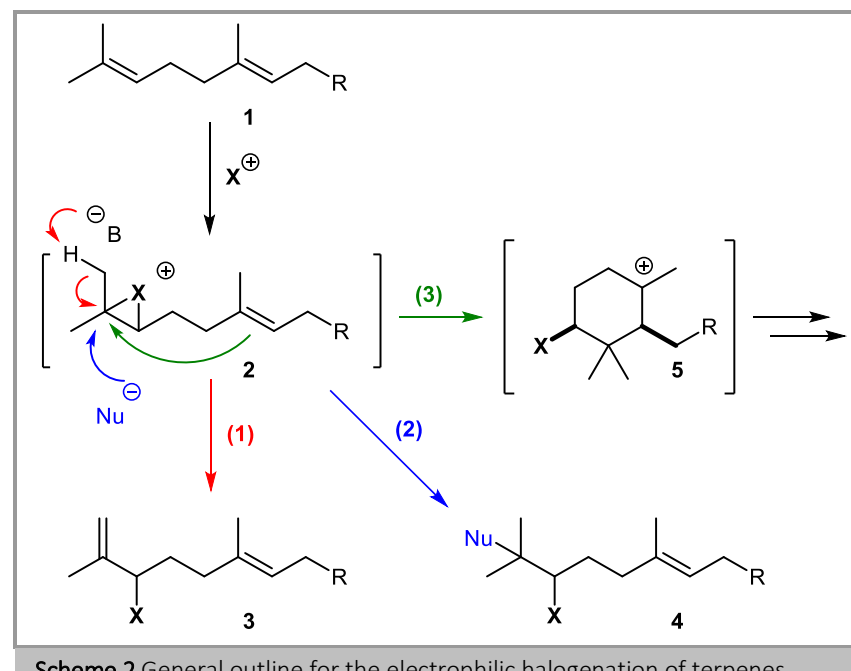

Scheme 2 General outline for the electrophilic halogenation of terpenes

From there, the subsequent steps can occur in a stereospecific manner, in particular if a cascade cyclization ensues. This implies that if the initial halogenation is enantioselective all stereogenic centers formed afterwards can be controlled. It should be mentioned that Braddock in 2013 and later Burns in 2017 demonstrated that an enantiospecific polyene cyclization could be achieved from such an enantiopure bromiranium ion. ${ }^{9}$ However, the latter did not come from a direct bromination but was generated from the corresponding bromohydrin ${ }^{9 a}$ or bromochloride. ${ }^{9 b}$

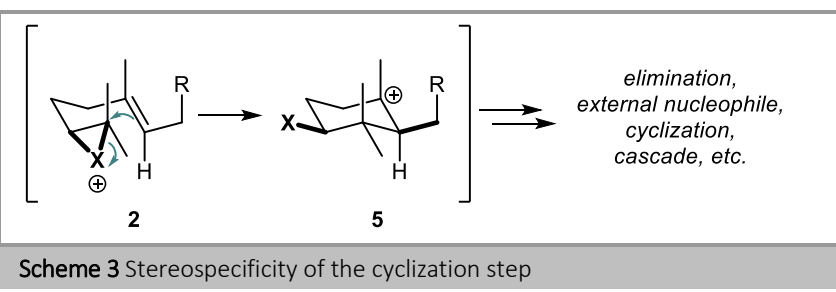

The aim of this review is to present the different methods that chemists have developed to efficiently initiate the direct halonium induced cyclization of polyenes, from seminal works to the most recent breakthroughs, including asymmetric variations and applications for the total synthesis of natural products. ${ }^{10}$

\section{Pioneering Studies}

In 1966, Van Tamelen reported that, unlike most terpene derivatives that would give bromohydrins under the same conditions, treatment of methyl farnesate $\mathbf{6}$ with NBS in a water/THF mixture also produced minor amounts of bromocyclized products 7 and 8 (Scheme 4, eq. 1). ${ }^{11}$ These compounds were identified as the major components of a fraction representing $12-15 \%$ yield. After selective saponification and further purification, only $4-5 \%$ of this fraction were found to be the bicyclic products 7. A similar cyclization was observed in 1975 by Nasipuri for the more nucleophilic $m$-anisyl derivative 9a (Scheme 4, eq. 2), which led to tricycle 10a in $10 \%$ yield under the same conditions (the major products being the acyclic dibromohydrins). ${ }^{12}$

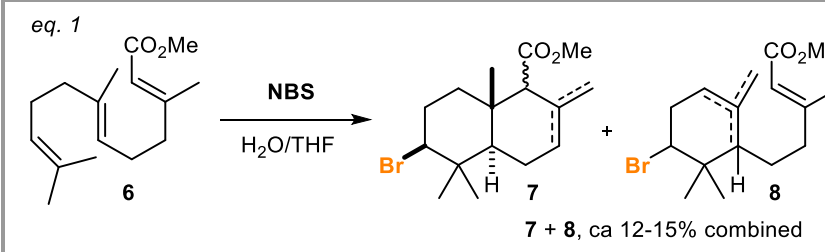

eq. 2

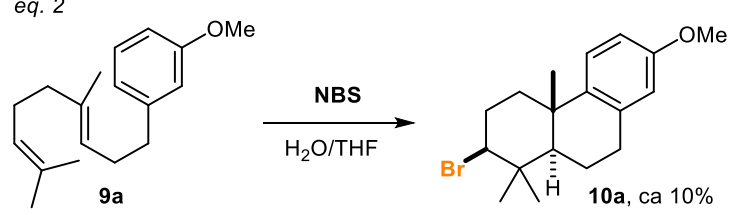

Scheme 4 First examples of bromocyclization of polyenes mediated by NBS

The following year Faulkner described the bromocyclization of geranyl acetate 11a using bromine (Scheme 5 , eq. 1). ${ }^{13}$ The use of bromine along with tin(IV) bromide mostly led to dibrominated products although $16 \%$ of cyclized product 12a could be isolated. Instead of $\mathrm{SnBr}_{4}$, silver(I) tetrafluoroborate was used to scavenge the bromide ions responsible for the dibromination of the olefin allowed the yield to reach $20 \%$. Applying this second protocol to geranylacetone $\mathbf{1 3}$ gave bicyclic enol ether 14 in 20\% yield (Scheme 5, eq. 2). Hydrolysis of the enol, vinylation of the resulting ketone followed by acidic treatment eventually furnished 10 -bromo- $\alpha$-chamigrene (15).

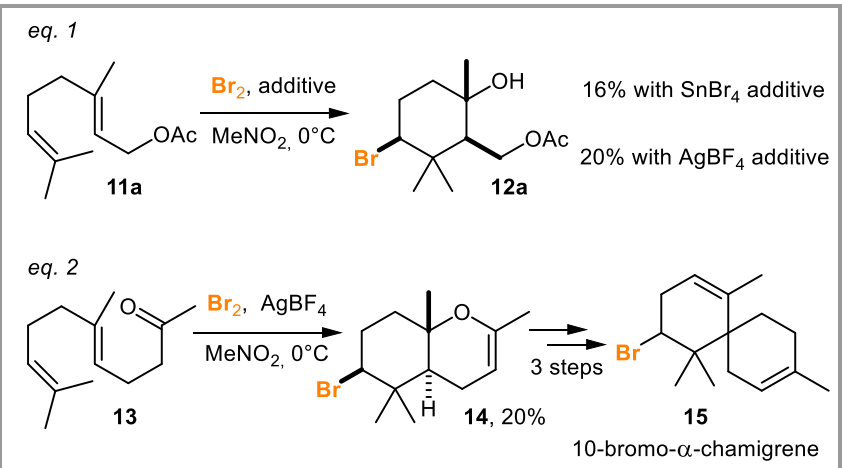

Scheme 5 Faulkner's bromocyclization of geranyl acetate and total synthesis of 10 -bromo- $\alpha$-chamigrene

These seminal studies showed that the total synthesis of halogenated polycyclic natural products could be achieved by a straightforward biomimetic strategy. Yet, they also highlighted that, while feasible using standard reagents such as $\mathrm{Br}_{2}$ or NBS, the bromocyclization pathway was not favored and would require some kind of additive (a silver salt for Faulkner) or specifically designed reagents to increase its efficiency.

\section{Use of Specific Reagents}

\subsection{TetraBromoCyclohexadienOne (TBCO)}

As the initial electrophilic halogenation of the terminal double bond would yield a highly reactive cationic intermediate, to promote carbocyclization other species in the reaction need to be less nucleophilic than the internal olefin. Taking this into consideration, Kato proposed a combination of 2,4,4,6tetrabromo-2,5-cyclohexadienone 16 (TBCO) and an aluminum(III) halide to promote the bromocyclization of polyenes. ${ }^{14}$ The Lewis acid would trigger the generation of a bromonium ion along with aluminate complex $\mathbf{1 7}$ which is a rather poor nucleophile (Scheme 6, eq. 1). When applied to 
geranyl cyanide 18, these conditions gave $15 \%$ of the bromocyclized products 19 (Scheme 6, eq. 2). In this setting, the nucleophilic trapping of the carbocation by a bromide only happens after the cyclization. In the absence of $\mathrm{AlBr}_{3}$, no cyclization took place and the dibromination of the terminal double bond of 18 occurred quantitavely. ${ }^{15}$ In contrast, the conditions reported by Van Tamelen (Scheme 4, eq. 1) ${ }^{11}$ only gave the corresponding bromohydrin. Additionally, if TBCO is used in conjunction with cetyltrimethylammonium bromide, only the dibromination takes place. ${ }^{16}$ eq. 1<smiles>O=C1C(Br)=CC(Br)(Br)C=C1Br</smiles><smiles>CO[N+](=O)CC(C(C)(C)C)C(C)(C)C</smiles>
$\mathrm{Br}^{\oplus}+$<smiles></smiles>

eq. 2<smiles>CC1=CCCC(C)=CC1</smiles>

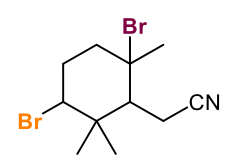

$19,15 \%$
Scheme 6 Activation of $\mathrm{TBCO}$ with $\mathrm{AlBr}_{3}$ and bromocyclization of geranyl cyanide

TBCO was also used for the biomimetic synthesis of natural products, which will be covered in the dedicated section below.

\subsection{Bis(pyridine)iodonium tetrafluoroborate}

Bis(pyridine)iodonium tetrafluoroborate was developed in 1985 by Barluenga as a practical reagent for the 1,2iodofunctionalization of olefins, ${ }^{17}$ and it proved suitable for the iodocarbocyclization of several polyenes. When very simple dienes such as hexa-1,5-diene 20a and hepta-1,6-diene 20b were subjected to the Barluenga's reagents and tetrafluoroboric acid the iodocyclization took place in a 6-endo or 6-exo fashion to give fluorocyclohexanes $\mathbf{2 1}$ or $\mathbf{2 2}$ respectively (Scheme 7). ${ }^{18}$ While iodocarbocyclization had been previously described with molecular iodine in $\mathrm{CCl}_{4}$, it was limited to one 1,6-diene containing a central gem-dialkyl carbon. Under these conditions, 20a and 20b only led to linear polyiodinated products. ${ }^{19}$

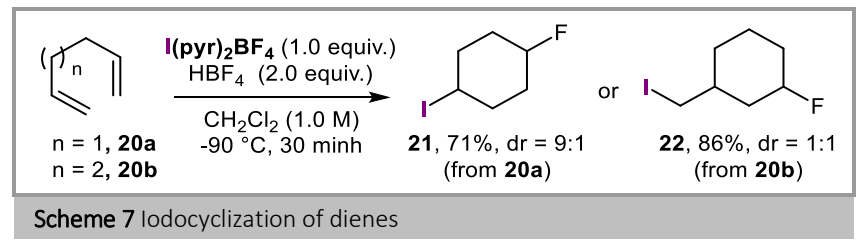

When phenyl-geranyl ether $\mathbf{2 3}$ was submitted to Barluenga's reagent, iodo-chromane $\mathbf{2 4}$ was obtained with an excellent yield. ${ }^{20}$ To explain the formation of $\mathbf{2 4}$ and other rearranged products the authors proposed that the iodocarbocyclization would initially lead to an oxetanium intermediate. Substrate $\mathbf{2 3}$ would thus give $\mathbf{2 5}$ that can then yield $\mathbf{2 4}$ (Scheme 8, eq. 1). This protocol can even be applied to longer polyenes such as farnesyl derivative 26 to give tetracyclic tetrahydroquinoline 27 in $41 \%$ yield, in this case without rearrangement (Scheme 8, Eq.2).

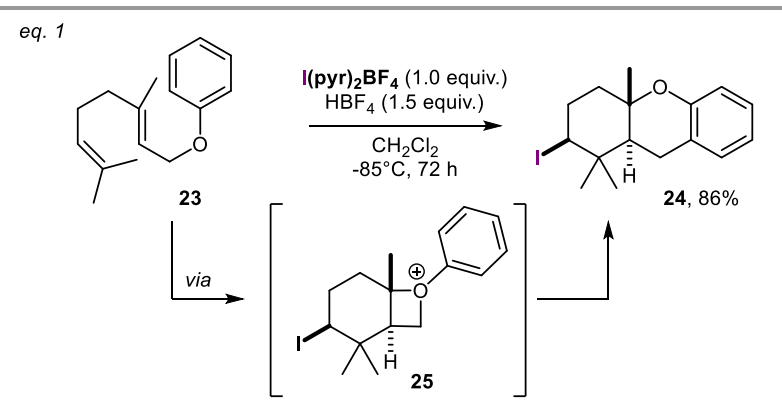

eq. 2

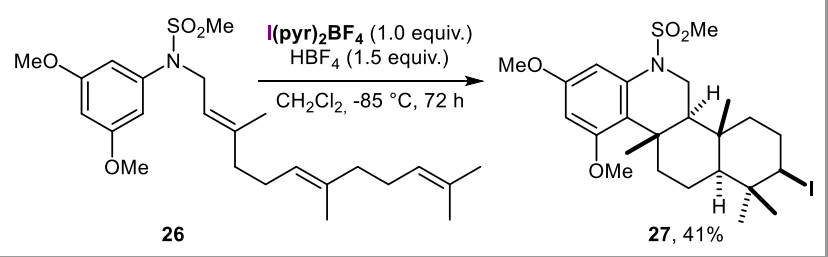

Scheme 8 lodocyclization of geranyl and farnesyl derivatives with Barluenga's reagent

\subsection{Use of Halodiethylsulfoniums}

\subsubsection{Bromodiethylsulfonium Bromopentachloro antimonate (BDSB)}

For the development of bromodiethylsulfonium bromopentachloroantimonate (BDSB) in 2009, the group of Snyder hypothesized that a controlled polyene cyclization required a highly activated cationic bromonium source without any nucleophilic anionic species being present. ${ }^{21}$ For this purpose they chose to synthetize and study the reactivity of various bromosulfoniums salts and eventually selected BDSB. BDSB is obtained by reaction of $\mathrm{Br}_{2}$ with $\mathrm{SbCl}_{5}$ and $\mathrm{Et}_{2} \mathrm{~S}$ in 1,2dichloroethane at $-30{ }^{\circ} \mathrm{C}$ (Scheme 9), ${ }^{22}$ it is fairly convenient to isolate and can be stored for some time before being used.

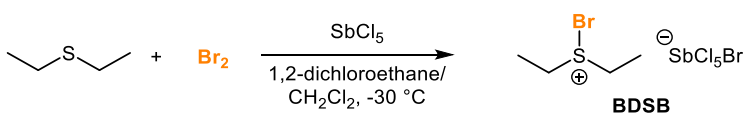

Scheme 9 Synthesis of BDSB

This specifically designed reagents turned out to give exquisite results in terms of chemoselectivity and yields on a very broad range of substrates, especially compared to the existing methods at that time (Table 1). Ten years later, it remains the gold standard for the racemic bromo-cyclization of polyenes. Electron-poor substrates such as geranyl cyanide $\mathbf{1 8}$ or geraniol esters 11a, b and carbonate 11c selectively gave the corresponding monocyclic products with excellent yields (entries 1-4). Stronger electron-withdrawing groups (CN, $\mathrm{OCOCF}_{3}$ ) favored a final elimination to give cyclohexenes $\mathbf{2 8}$ and 29 (entries 1, 3), whereas internal nucleophilic trapping occurred for acetate 11a and carbonate 11c to give alcohol 12a (after hydrolysis) and cyclic carbonate $\mathbf{3 0}$, respectively (entries $2,4)$. 
Table 1 Reactivity of BDSB with a variety of polyenes and comparison with other methods

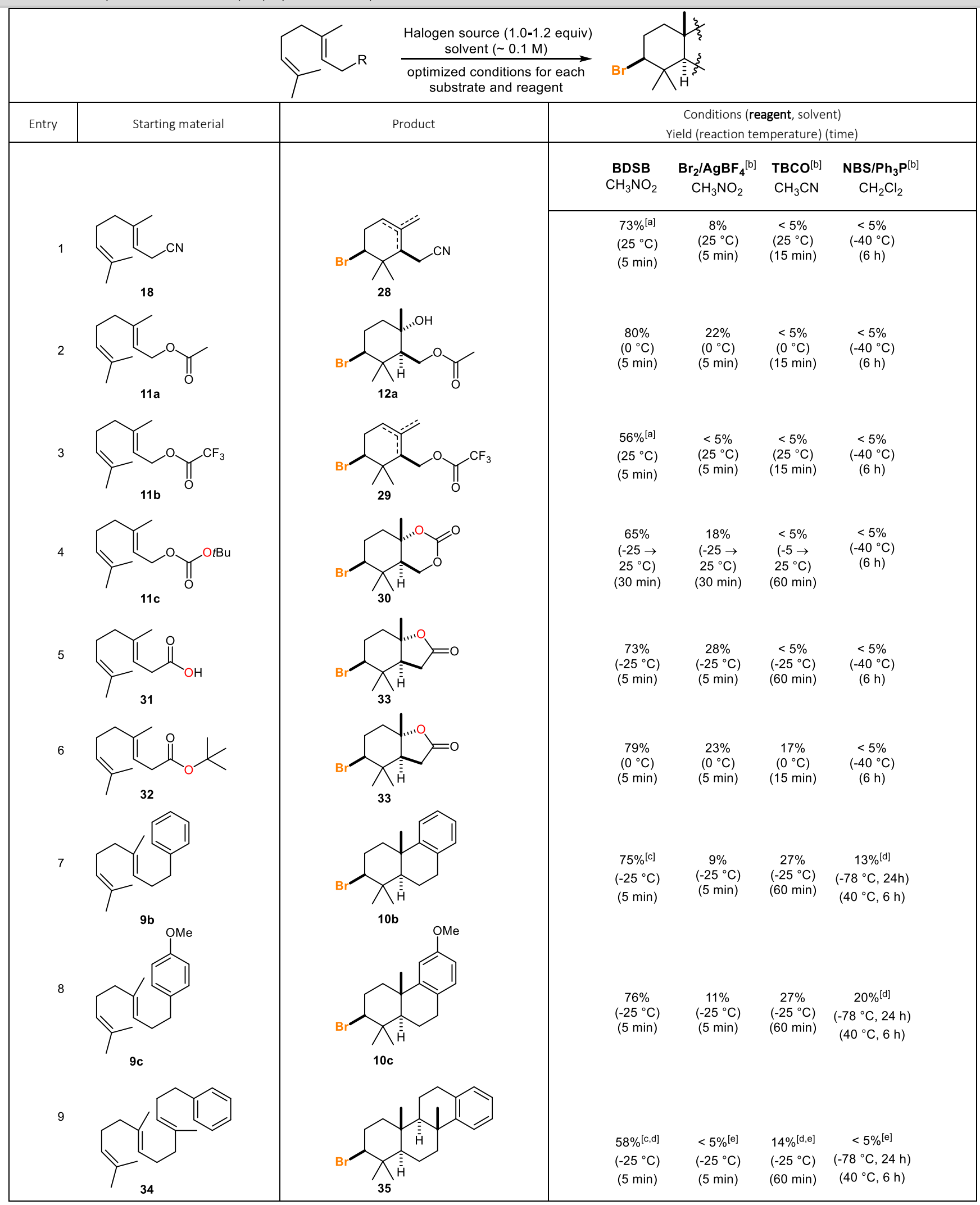

[a] Isolated as a mixture of alkene stereoisomers. [b] All yields deriving from this reagent were determined by NMR analysis using nitrobenzene as an internal standard since the desired material co-elutes with undesired side products. [c] Generated alongside some very minor diastereomers. [d] Yield includes partially cyclized material. [e] Complete cyclization promoted by the addition of $\mathrm{CH}_{3} \mathrm{SO}_{3} \mathrm{H}$ at the end of the reaction. 
Homogeranic acid $\mathbf{3 1}$ and its $t$-butyl ester $\mathbf{3 2}$ reacted equally well to give 6,5-bicyclic lactone $\mathbf{3 3}$ (entries 5, 6). One striking feature of BDSB is that it can directly convert electron-rich substrates such as homogeranylphenyl derivatives $\mathbf{9 b}, \mathbf{c}$ and even farnesyl substrate $\mathbf{3 4}$ to the fully cyclized products $\mathbf{1 0 b}, \mathbf{c}$ and 35 without having to resort to an additional acidic treatment (entries 7-9).

\subsubsection{IDSI and CDSC}

Following the development of BDSB, the group of Snyder studied the synthesis of iodo- and chloro-variants of their reagent. ${ }^{23}$ Reaction of iodine with pentachloroantimonate and diethyl sulfide was optimized to allow the isolation of a chlorinebridged dimer that was termed IDSI (Scheme 9, eq. 1). This dimer was less stable than BDSB - a quick decomposition occurred at room temperature to give $\mathrm{ICl}, \mathrm{SbCl}_{5}$ and $\mathrm{Et}_{2} \mathrm{~S}-$ but suitable to carry out iodination reactions (see below). Following a similar protocol with chlorine gave chlorodiethylsulfonium hexachloroantimonate (CDSC), which was structurally analogous to BDSB (Scheme 9, eq. 2).

$$
\begin{aligned}
& \begin{array}{cc}
\text { eq. } 1 & \mathrm{I}_{2} \text { (0.5 equiv.) } \\
& 1,2 \text {-dichloroethane }
\end{array}
\end{aligned}
$$

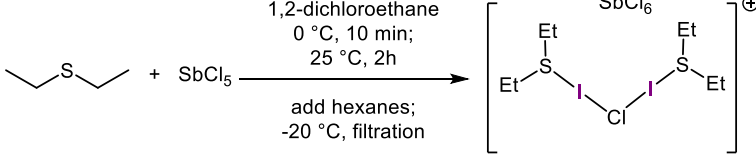

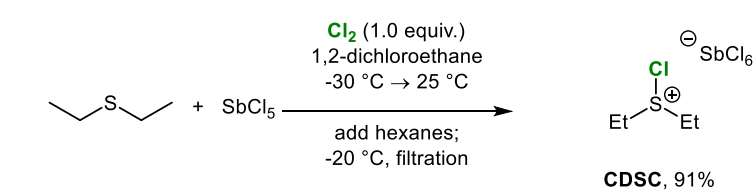

Scheme 10 Synthesis of IDSI and CDSC.

Despite its minor drawbacks, IDSI could be used for the cyclization of several polyenes (Table 2, entries 1-3). For electron-rich benzylgeranyl $\mathbf{9 c}, \mathbf{d}$ and for benzylfarnesyl $\mathbf{3 4}$ the desired tri- and tetracycles $\mathbf{3 6 c}$, $\mathbf{d}$ and $\mathbf{3 7}$ respectively were obtained in good yields (entries 1-3)., even though for the latter the final cyclization required the addition of methane sulfonic acid. Protected phenolic derivative $\mathbf{3 8}$ underwent a cascade cyclization process to give tricycle $\mathbf{3 9}$ (with the loss of one MOM group, entry 4), Electron-poor compounds such as nitrile 18, geranyl acetate 11a and carbonate $\boldsymbol{E}-\mathbf{1 1} \mathbf{c}$ reacted in a similar fashion to that observed with BDSB, yielding cyclohexenes $\mathbf{4 0}$, tertiary alcohol 41a and cyclic carbonate 42, respectively (entries 5-7). Finally, neryl carbonate $\boldsymbol{Z}-\mathbf{1 1} \mathbf{c}$ also reacted to give the trans, cis isomer 42' in moderate yield, thus confirming the stereospecificity of the transformation (entry 8).

The CDSC reagent could also be applied for various cyclizations, which, although the scope was more limited and the yields more modest, represented the first report of an ionic chloronium induced polyene cyclization (Table 3). Hence, homogeranylbenzene $\mathbf{9 b}$ gave the chlorinated tricycle $\mathbf{4 3 b}$ in $46 \%$ yield (entry 1). The reagent also promoted the cyclization of electron-poor substrates such as geranyl acetate 11a to give 44 (entry 2), or homogeranic acid $\mathbf{3 1}$ and its t-butyl ester 32, both yielding lactone $\mathbf{4 5}$ with modest yields (entries 3,4 ).

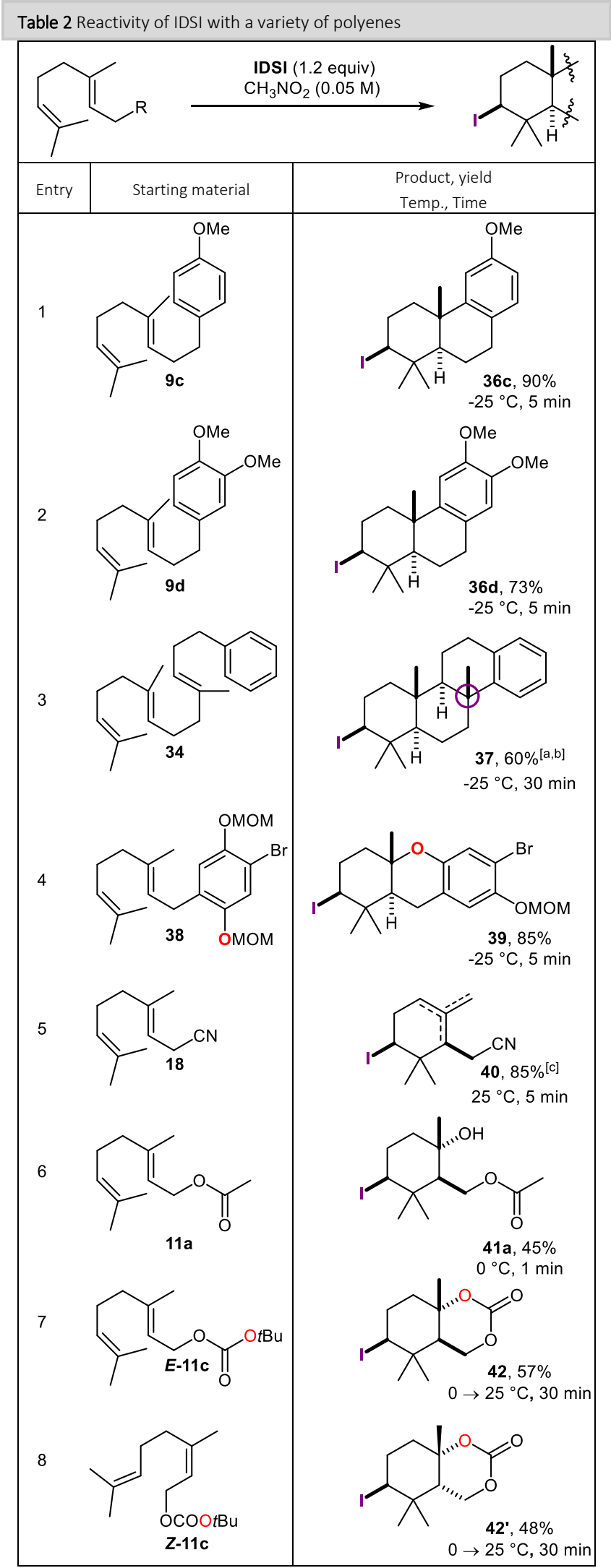

[a] Isolated as a 2:1 mixture of inseparable stereoisomers about the highlighted carbon atom favoring the drawn diastereoisomer. [b] $\mathrm{MeSO}_{3} \mathrm{H}$ (15 equiv.) added with $1 \mathrm{~h}$ of additional stirring to promote the final cyclization. [c] Produced as a 8.5:1.4:1.0 mixture of tri, tetra and disubstituted alkene isomers. 
Table 3 Reactivity of CDSC with a variety of polyenes

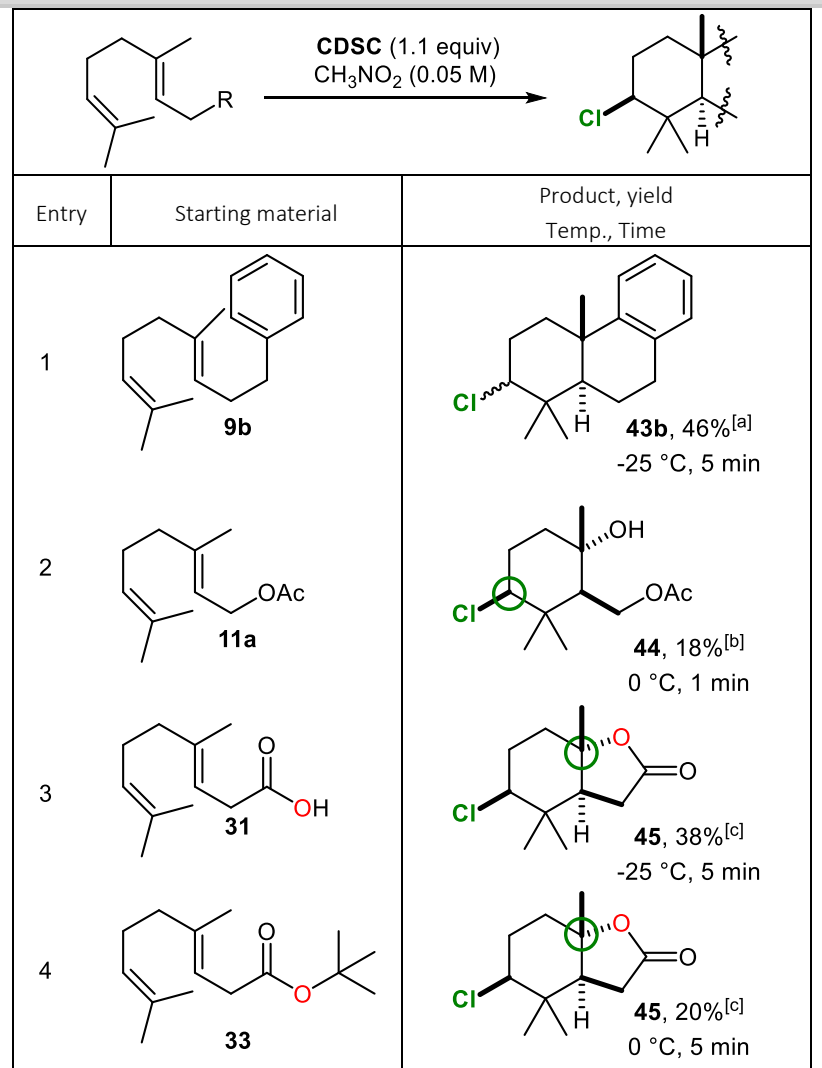

[a] Isolated as a 1.0:1.0 mixture of inseparable stereoisomers. [b] Isolated as a 2.2:1.0 mixture of separable diastereoisomers at the highlighted carbon favoring the drawn product. [c] Produced as a 4.0:1.0 mixture of separable diastereomers at the highlighted carbon favoring the drawn product.

\subsection{Miscellaneous}

\subsubsection{Trimethylphenylammonium perbromide}

Trimethylphenylammonium perbromide (TMPAP) is a soluble and stable electrophilic bromination reagent, ${ }^{24}$ which has been used for the transannular bromocyclization of costunolide $\mathbf{4 6}$ (Scheme 11). ${ }^{25}$ An excellent overall yield of $95 \%$ was obtained for the formation of tricyclic $\mathbf{4 7}$ as a mixture of olefin isomers with the major one $(70 \%)$ being the exo-isomer. The use of TMPAP greatly increases the efficiency of the product formation compared to NBS, which had previously been reported to give a very complex mixture after reaction with the analogous dihydrocostunolide. ${ }^{26}$ Water was excluded to prevent the formation of the tertiary alcohol by nucleophilic trapping of the carbocation and pyridine was added to scavenge any strong acid that would lead to the corresponding proton-induced transannular cyclization. ${ }^{25}$

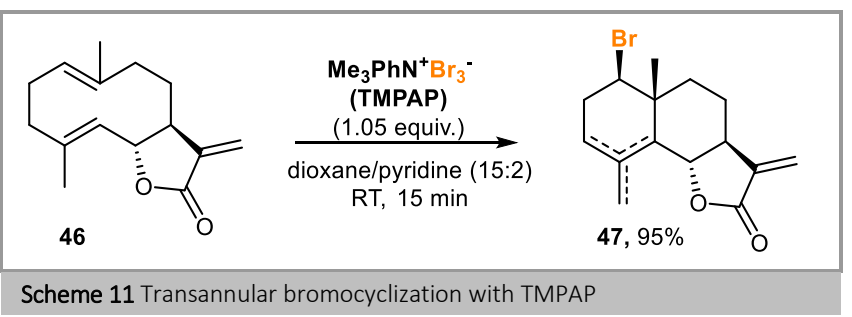

\subsubsection{Vanadium bromoperoxidase}

Since the aforementioned bromocyclizations were modeled after Nature's, it was somewhat tempting to try and reproduce those transformations using a halogenase enzyme as catalyst. ${ }^{27}$ The group of Butler isolated and cloned a vanadium bromoperoxidase (V-BrPO) from red algae and submitted several linear terpenes to this enzyme in the presence of potassium bromide and hydrogen peroxide. ${ }^{28}$ Thus, geranyl acetate 11a gave a racemic mixture of endo- and exo-bromocyclohexenes 48 in moderate yield (10-20\%, Scheme 12, eq 1) and geranyl acetone $\mathbf{1 3}$ gave the racemic bicycle $\mathbf{1 4}$ (Scheme 12, eq 2) that was previously reported by Faulkner (Scheme 5, eq. 2). ${ }^{13}$

$$
\text { }
$$
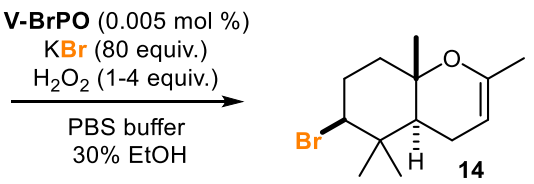

Scheme 12 Butler's enzymatic bromocyclization of geranyl acetate and geranyl acetone

\subsubsection{Bromiranium}

Following the strategy of having a stabilized bromonium with a weakly coordinating anion, the group of Hennecke designed the synthesis of the (stable) bromiranium salt of adamantylidene adamantane with a BArF (tetrakis[3,5bis(trifluoromethyl)phenyl]borate) counterion (Scheme 13). ${ }^{29}$ This reagent promoted the bromination of phosphines and was also used for the bromocyclization of three homogeranylarene derivatives (9) to give the corresponding tricyclic products $\mathbf{1 0}$ with modest to good yields. Hexamethyldisilazane was used to prevent the formation of the very strong acid HBArF that can induce cationic cyclization of the substrates.

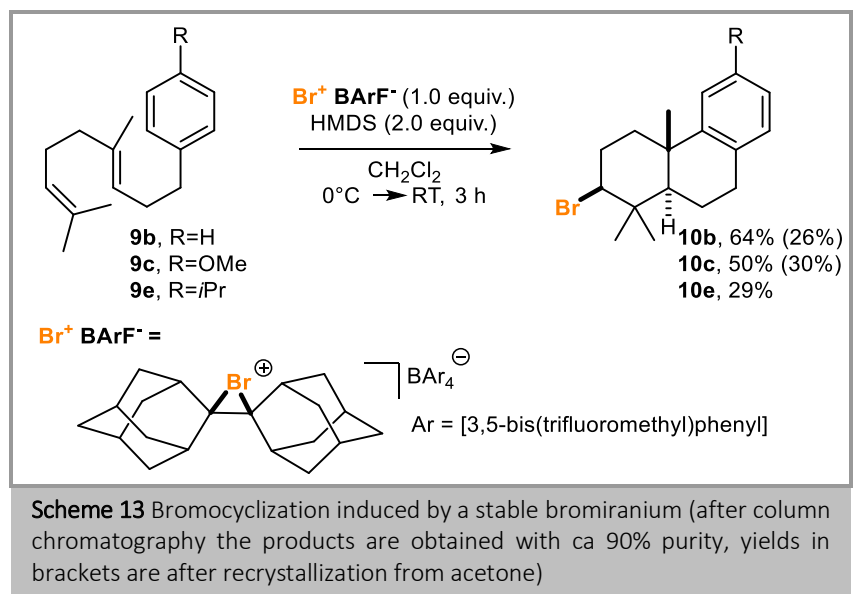

3.4.4 Bis(tert-butylcarbonyloxy)iodobenzene/Triethylsilylbromide 
In order to generate an electrophilic bromination species that would selectively trigger the cyclization of polyenes and suppress the formation of the unwanted linear brominated products, the group of Cariou screened various combinations of hypervalent iodine(III) reagents ${ }^{30}$ as oxidants with different bromide sources. ${ }^{31}$ The rather soluble bis(tertbutylcarbonyloxy) iodobenzene was selected so the reaction could be run at low temperature $\left(-78^{\circ} \mathrm{C}\right)$ in nitroethane, thus preventing undesired side reactions, and because the oxidation of the bromide would liberate pivalate, a rather mediocre nucleophile that would not compete with the internal double bond. As for the bromide source, triethylsilylbromide was chosen because it was soluble and relatively easy to handle. Using this combination of reagents allowed to selectively promote the carbocyclization process of various homogeranylbenzenes $\mathbf{9}$ and, after treatment of the crude with a strong acid, the desired tricyclic products $\mathbf{1 0}$ were isolated in moderate to good yields (Scheme 14).

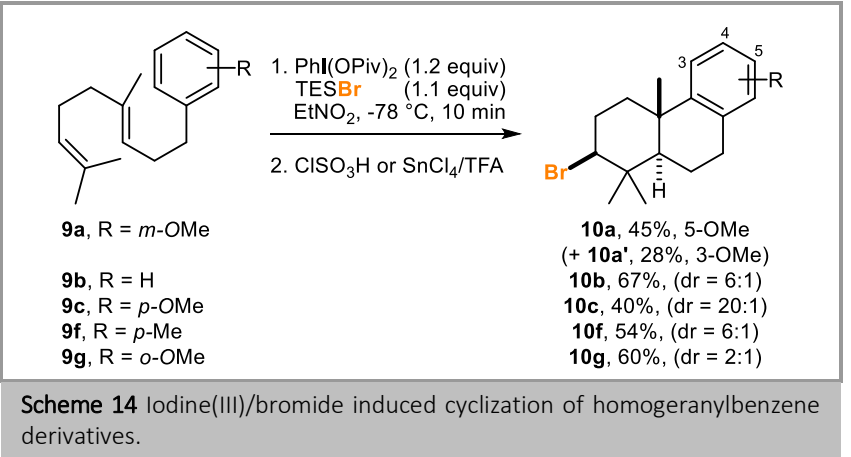

The reaction conditions could also be applied to geranylaryl derivatives 4 to give snyderol type bromocyclohexenes 49a, b or, if an $o$-phenol moiety was present, to an isocymobarbatol ${ }^{32}$ like bromo-hexahydroxanthene 50a (Scheme 15). Additionally, homofarnesyl derivative $\mathbf{3 4}$ could be converted into tetracyclic compound 35, albeit with a modest yield.

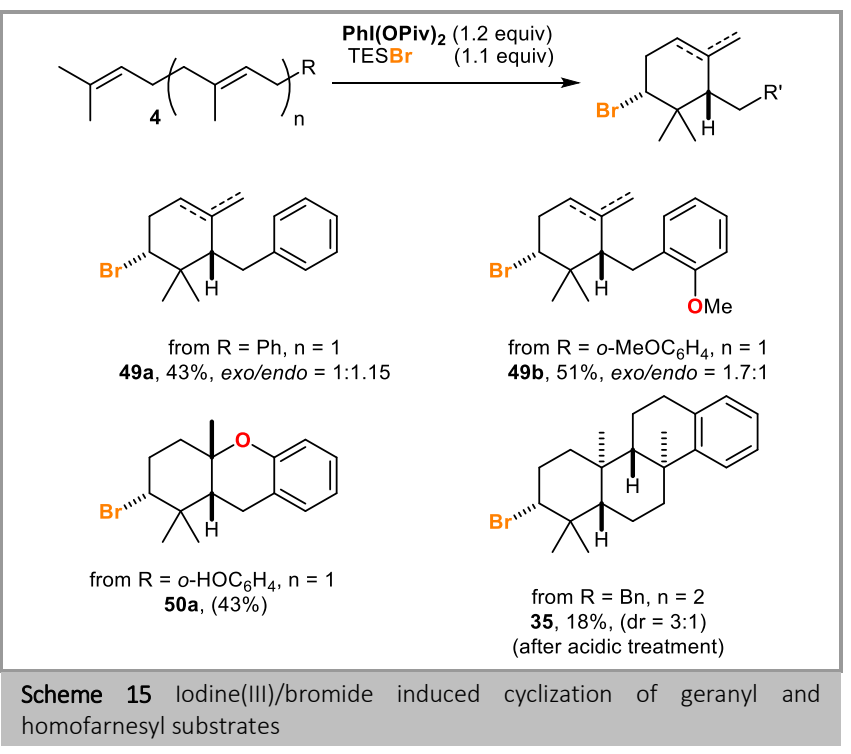

Finally, it is worth noting that while this combination of reagents specifically promotes the polyene cyclization process, the use of other iodine(III) reagents with other bromides, ${ }^{31}$ chlorides or iodides, ${ }^{33}$ rather leads to various possible linear halogenated products in a selective fashion.

\section{Use of $\mathbf{N}$-Halo Amides}

\subsection{Activation with a phosphorus derivative}

\subsubsection{Phosphines}

A considerable breakthrough in the field of halocyclization of polyenes came in 2007 when Ishihara described the iodo- and bromo-cyclization of benzyl-geranyl derivatives using a combination of the corresponding $N$-halosuccinimide with a nucleophilic promoter such as a phosphine. ${ }^{34}$ In sharp contrast with what had previously been observed, ${ }^{11}$ reacting homogeranyltoluene 9 f with NBS or NIS in dichloromethane in the presence of $30 \%$ of tri- $n$-butylphosphine allowed, after acidic treatment, the isolation of the desired iodo- (36f) and bromo (10f) tricycles in good to quantitative yields (Scheme 16). Other phosphines and phosphites could also promote the reaction, with lower yields, but nucleophilic amines such as DBCO and DMAP were inefficient.

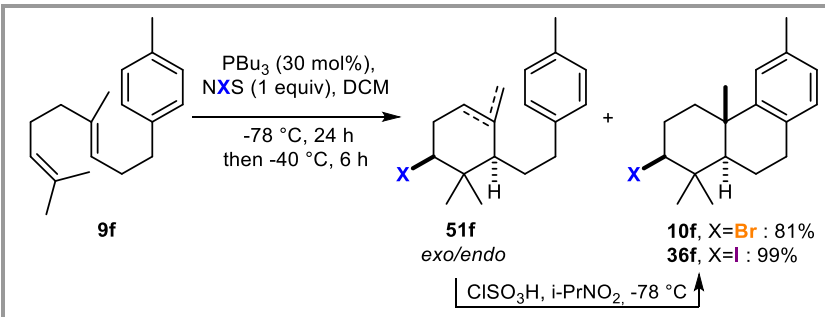

Scheme 16 Halocyclization with NXS promoted by a phosphine

Ishihara proposed that the nucleophilic activation of the $\mathrm{N}$ halosuccinimide by the phosphine would give phosphonium salt $\mathbf{5 2}$ as the actual halogenation species that would then react with the polyenic substrates 9 (Scheme 17). The close vicinity between the nucleophilic promoter and the halogen in the active species was considered determinant for the development of an asymmetric version of this reaction by the same authors (see dedicated section below). Setting the absolute configuration of haliranium 53 then induces the configuration of the stereogenic centers formed during the subsequent stereospecific cyclization process.

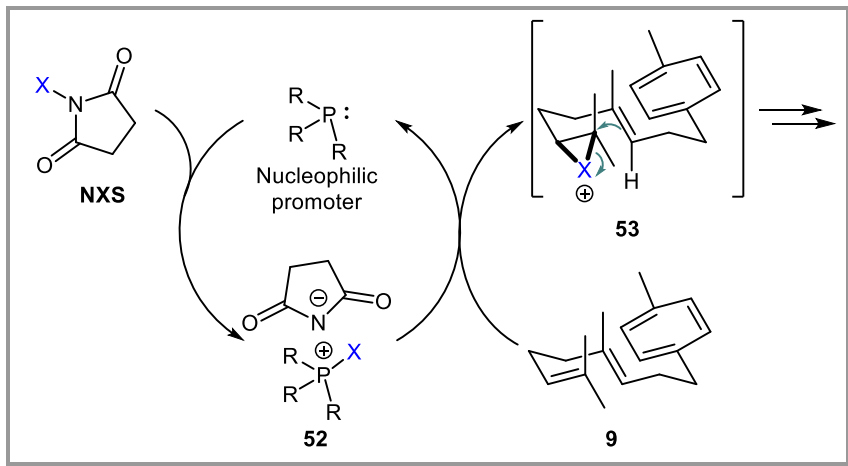

Scheme 17 Mechanism proposal for the nucleophilic activation of NXS

\subsubsection{Phosphite-urea}

The major drawbacks of Ishihara's protocol were the need for high catalyst loading (up to $100 \mathrm{~mol} \%$ for the asymmetric variant) and the inferior (in terms of yield and ee) results 
obtained for the bromination reaction with NBS. ${ }^{34}$ In order to overcome these limitations they later designed bifunctionnal phosphite-urea catalyst 54 (Scheme 18). ${ }^{35}$ Its reaction with NBS or with the more reactive 1,3-dibromo-5,5-dimethylhydantoin (DBDMH) would give complex $\mathbf{5 5}$ that would simultaneously bear the phosphonium bromide reactive center and sequestrate the imidate to prevent unwanted side-reactions. In particular, addition of the imidate onto the phosphonium would be detrimental since it would liberate bromides that might lead to the formation of the dibromo products.

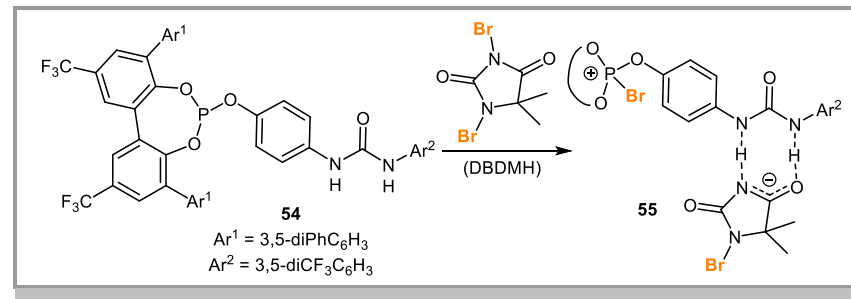

Scheme 18 Dual activation of DBDMH with a phosphite-urea catalyst

This carefully designed system allowed to perform the reaction with a low catalyst loading $(0.5 \mathrm{~mol} \%)$ and a high efficiency for several homogeranylarenes 9, yielding the desired tricyclic products $\mathbf{1 0}$ in the $90 \%$ yield range after full cyclization in acidic conditions (Scheme 19).

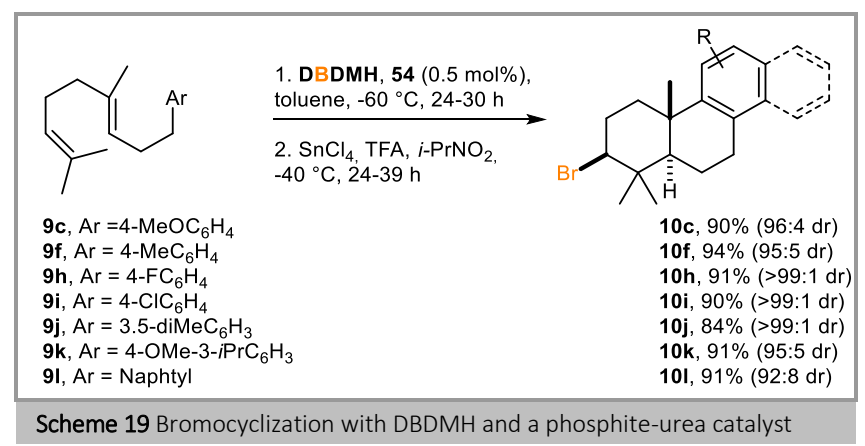

These conditions were subsequently applied to 2geranylphenols to give isocymobarbatol-like bromohexahydroxanthenes. 36

\subsubsection{Phosphoramidite}

Shortly after Ishihara's report, McErlean disclosed the use of phosphoramidite (S)-TCPT (56) as a promoter for the monocyclization of various geranyl derivatives with NBS. ${ }^{37}$ In toluene the reaction led to the cyclohexene derivatives as major product in all cases (Scheme 20). In contrast to BDSB (see Table 1), benzyl derivative $\mathbf{9 b}$ and acylgeraniols 11a, $\mathbf{d}$ afforded cyclohexenes 58b and 48a, d. Unfortunately, although the promoter is chiral, no optically active products could be isolated.

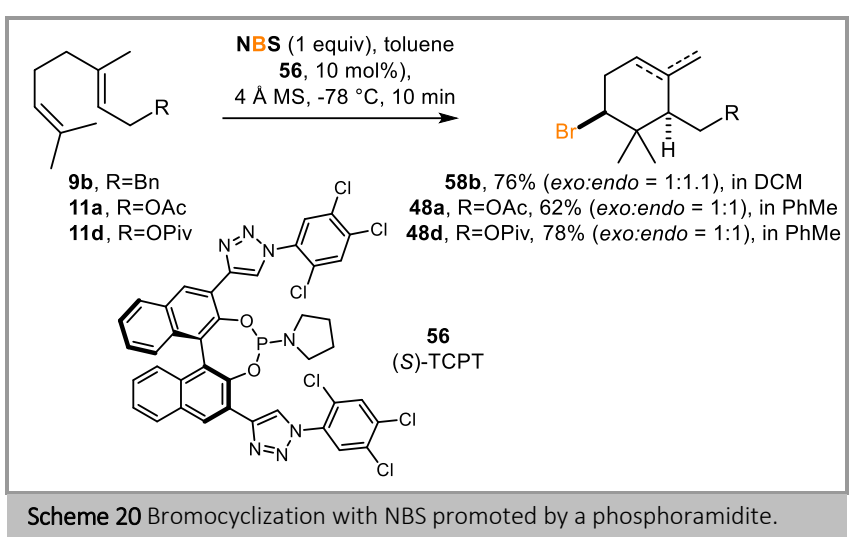

\subsection{Activation with an amine}

While Ishihara had shown that neither DABCO nor DMAP were suitable activators, the group of Yamamoto briefly reported that 2,4,6-trimethylaniline could promote the bromocyclization of 9b into 10 b in $66 \%$ yield (after acidic treatment). ${ }^{38}$ After this single example the group of Gulder recently showed that hexafluoroisopropanol (HFIP) had a dramatic positive effect for the halocyclization of polyenes using $N$-haloamides such as NBS ( $42 \%$ of $\mathbf{1 0 b}$ from $\mathbf{9 b}$ in HFIP vs $8 \%$ in DCM). Even better yields (78\%) could be achieved in the presence of morpholine (as its HFIP salt)..$^{39}$ Using this simple setting a broad range of polyenes could undergo bromocyclization with excellent yields that compare favorably with those obtained with BDSB (Scheme 21).

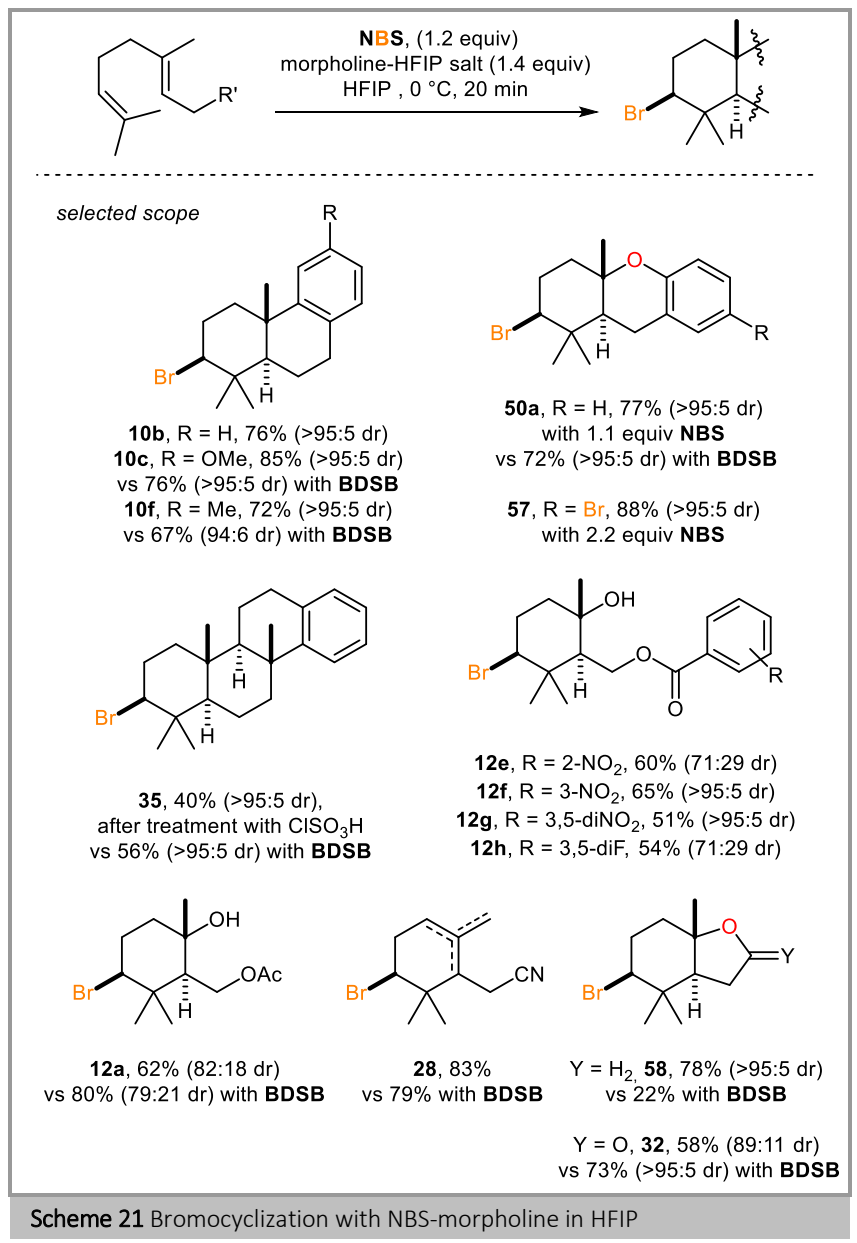


Similar to BDSB (Table 1), tricycles $\mathbf{1 0}$ were directly obtained from the starting homogeranylarenes $\mathbf{9}$, the farnesyl derivative 34 being the only one that required an additional acidic treatment to form tetracyclic product 35 (Scheme 21). Hexahydroxanthene 50a stemmed from the cyclization of $o$ geranylphenol with one equivalent of NBS whereas the reaction with two equivalents of NBS induced an additional bromination of the aryl ring (product 57). The reaction of geraniol esters gave the monocyclized tertiary alcohols 12a, e-h with good yields and stereoselectivities, while geranyl cyanide furnished a mixture of cyclohexenes (28). Finally, homogeraniol and homogeranic acid underwent a cascade cyclization to give tetrahydrofuran 58 and lactone 32, respectively.

This method was readily extended to the analogous iodocyclization with NIS, giving the desired products with good yields and diastereomeric ratios up to 95:5 (Scheme 22). Homogeranylarene substrates directly yielded the tricyclic compounds 36 while o-geranylphenol gave iodohexahydroxanthene 59. Following the general trend observed for bromocyclization, geranyl esters gave tertiary cyclohexanols 41a, $g$ and geranylcyanide gave cyclohexene 40. If an internal nucleophile is present, a cascade cyclization takes place giving an additional oxygenated ring, either a carbonate (60) or an ether (61).

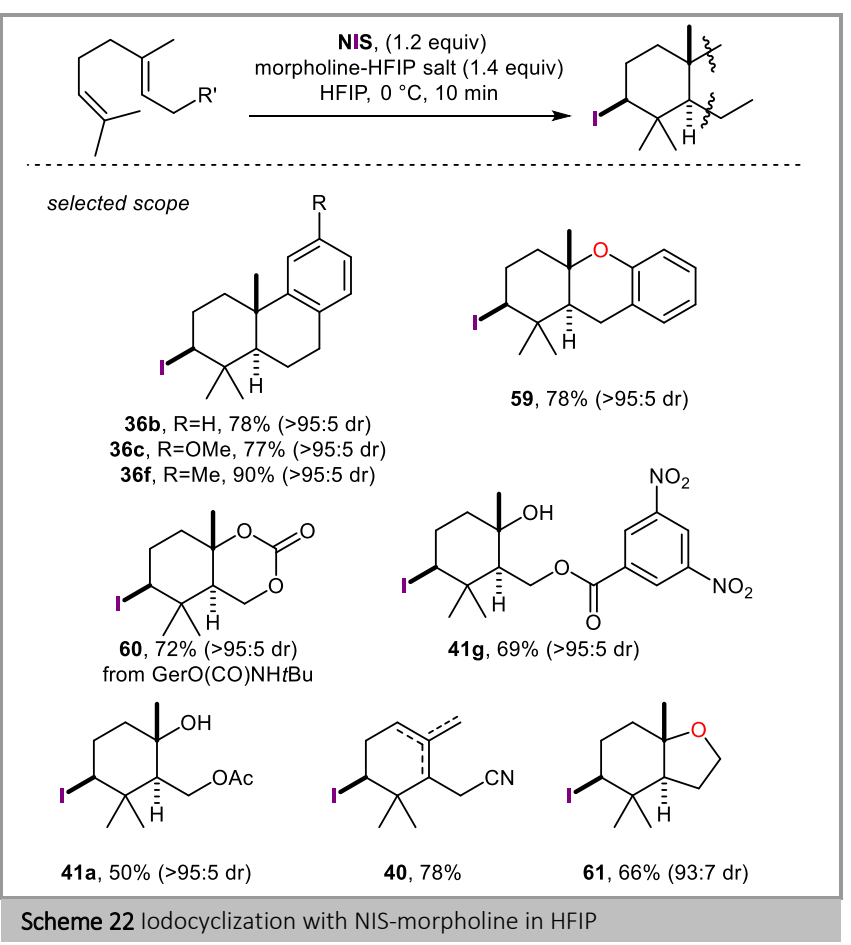

One key feature of this morpholine-HFIP system is that it could also be applied for the chlorocyclization of polyenes, using 1,3dichloro-5,5-dimethylhydantoin (DCDMH) instead of NCS. Although the scope and the yields are modest it represents a major improvement as until then only the CSDC was known to promote this type of chlorocyclization. In addition to the tricyclic chloro-products 43, previously obtained by Snyder, tetracycle $\mathbf{6 1}$ and oxygenated tricycle $\mathbf{6 2}$ could also be synthetized (Scheme 23).

Based on various mechanistic studies, the authors suggest several beneficial roles for the HFIP. First, as a strong hydrogen- bond donor it would stabilize the $N$-halo morpholine species, that was proposed as key reactive intermediate for halocyclization. Moreover, its high polarity would induce a prearrangement of the polyene through hydrophobic interactions. The apolar hydrocarbon chain would thus adopt a tight chair-like conformation, readily poised for cyclization.

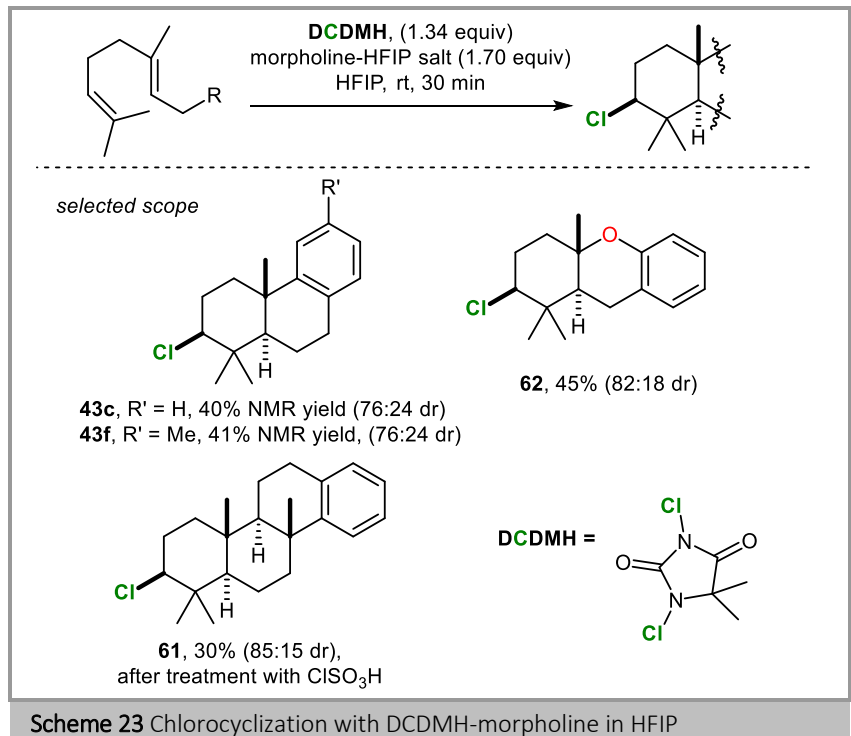

\section{Asymmetric Reactions}

The direct halonium-induced cyclization of polyenes already being a challenge per se, rendering this transformation enantioselective was even more arduous.40 Despite many accomplishments for the asymmetric halofunctionalization of alkenes, ${ }^{41}$ including cyclizations ${ }^{42}$ and dihalogenation, ${ }^{43}$ the asymmetric cyclization of polyenes remained elusive until 2007 and the work of Ishihara. ${ }^{344}$

\subsection{Ishihara's strategy}

\subsubsection{Iodocyclization}

After successfully devising conditions to activate NIS with a phosphorous nucleophile for the direct iodocyclization of polyene, the group of Ishihara went further by probing chiral inductors for the asymmetric version.

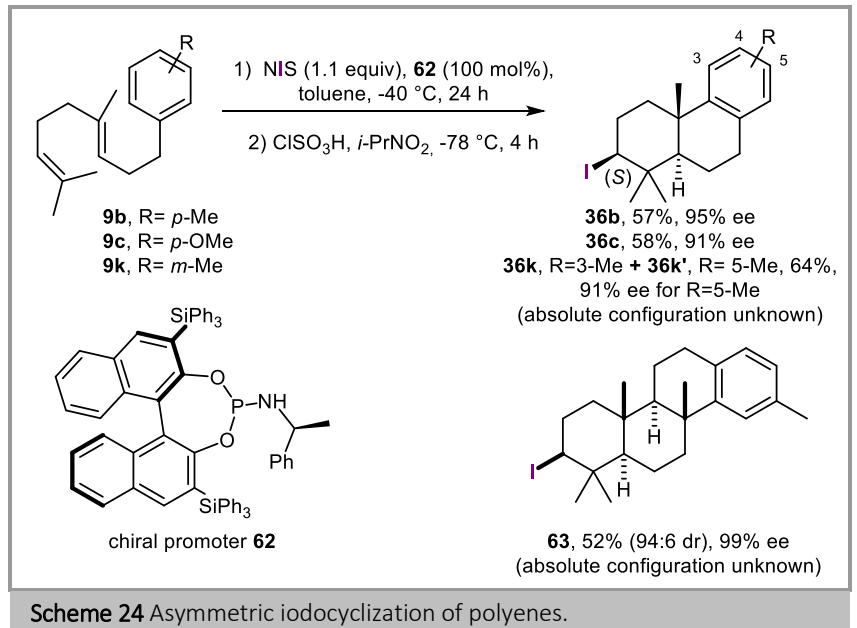

Scheme 24 Asymmetric iodocyclization of polyenes. 
A binol-derived phosphoramidite $\mathbf{6 2}$ was found to be the best promoter. Using one equivalent of $\mathbf{6 2}$ in combination with NIS in toluene, tricycles $\mathbf{3 6 b}, \mathbf{c}, \mathbf{k}$ and tetracycle $\mathbf{6 3}$ were obtained in good yields (after acidic treatment) and with enantiomeric excesses up to $99 \%$ (Scheme 24). As mentioned previously, Ishihara's mechanistic proposal stated that a phosphonium salt is the actual halogenation species. In toluene, reaction between NIS and promoter $\mathbf{6 2}$ would give a tight ion pair $\mathbf{6 4}$ which can be represented as 64' in Newman projection along the P-I bond (Figure 1). In this view, three segments of space can be delimited depending on steric hindrance. Iodination of the most reactive prenyl double bond, within the least hindered space would take place by a $S i$-face approach leading to the observed $S$ configuration in the final product. The subsequent stereocenters would be set during the following stereospecific cyclization process, whether it directly happens during the course of the reaction or only after treatment with a strong acid.

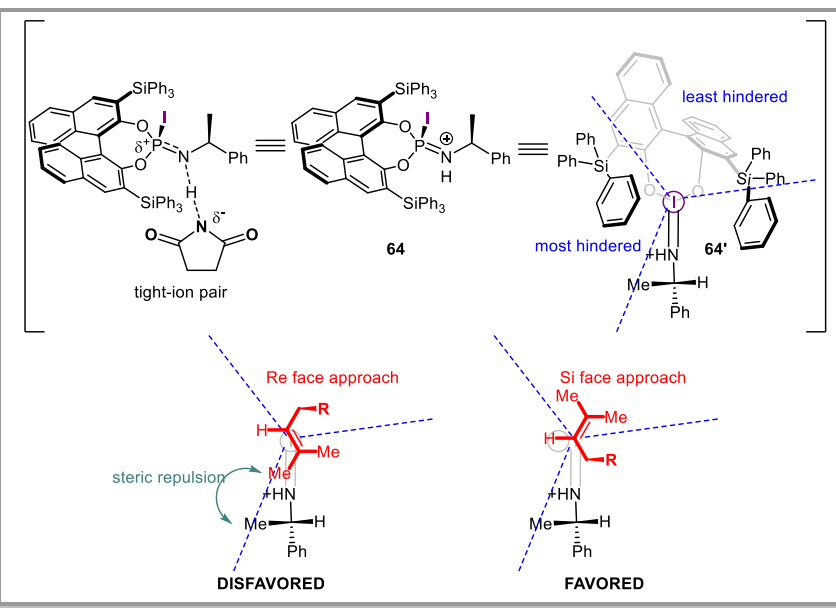

Figure 1 Mechanistic rationale proposed by Ishihara to explain the stereoinduction during asymmetric iodocyclization

\subsubsection{Bromocyclization}

After successfully rendering the bromocyclization of polyenes catalytic by using a phosphite-urea bifunctionnal catalyst (54, Figure 2), the group of Ishihara reported an enantioselective version of their strategy. 45 The catalyst backbone of $\mathbf{5 4}$ was expanded from a bi-phenyl to a bi-naphthyl and the 3,5diphenylphenyl substituents were exchanged for 3,5dipentafluorosulfanylphenyl groups (65).

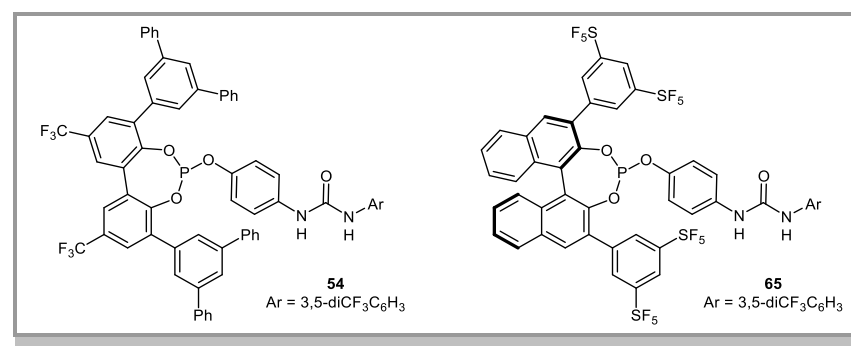

Figure 2 Ishihara's chiral phosphite-urea catalyst

Using $10 \mathrm{~mol} \%$ of this catalyst $\mathbf{6 5}$ with $\mathrm{N}$-bromophthalimide NBP (instead of the succinimide), cyclization of 2geranylphenols 66a-f afforded the monocyclized bromocyclohexenes 67a-f in good yields and moderate ee (Scheme 25). Tricycles 50a-e, $\mathbf{5 7}$ were also formed in the reaction and isolated in significantly lower yields and enantiomeric excess.

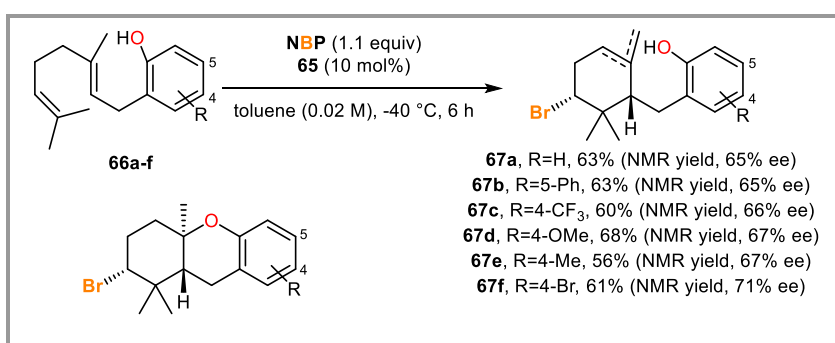

50a-e, 57 isolated in $16-28 \%$ yield and $13-29 \%$ ee

Scheme 25 Asymmetric bromocyclization of geranylphenols

However, when the monocyclic compounds $\mathbf{6 7}$ were converted to the tricyclic products $\mathbf{5 0}$, using triflic acid at low temperature in $i-\mathrm{PrNO}_{2}$ the enantiomeric excesses remained unchanged. This observation led the authors to assume that the single cyclization and the cascade cyclization did not arise from the same process, and the transition states involved were likely to be different. The major process, i.e. the monocyclization, would occur via $\mathbf{T S}_{\text {mono }}$ (Figure 3). In this transition state, an H-bond is established between the phenol and the urea moiety. This stabilizes the TS and precludes $\mathrm{O}$-cyclization, favoring the formation of the enantioenriched monocyclized product. The tricyclic products were proposed to arise from the less stable $\mathbf{T S}_{\text {casc, }}$ where no hydrogen bond is present and the phenol is thus more nucleophilic.

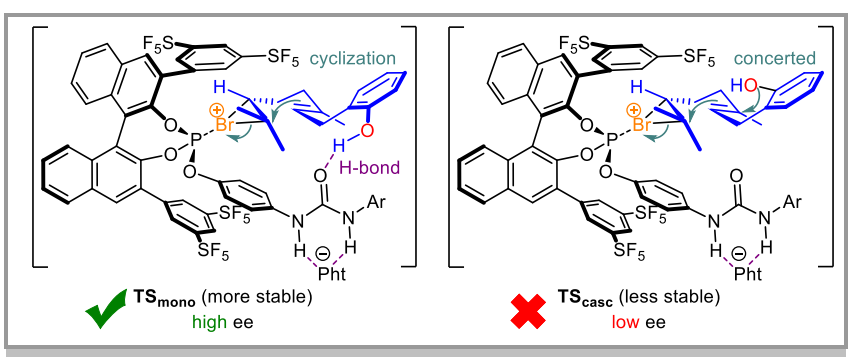

Figure 3 Comparison between mono-cyclization and cascade transition states

\subsection{Yamamoto's Strategy}

Ten years after Ishihara's group initial report ${ }^{34}$ and taking cues from subsequent studies, 35,36 the group of Yamamoto was eventually able to devise a suitable catalyst for the asymmetric bromocyclization of polyenes. ${ }^{46}$ After optimization, binol-based thiophosphoramide $\mathbf{6 8}$ was selected as the best catalyst in combination with DBDMH (Figure 4). As with Ishihara's phosphite-urea catalyst, a dual activation of the halogenation reagent was postulated. However, here the Lewis base is the sulfur and not the phosphorous whilst the Brønsted acid is the triflimide. The Lewis basicity of the sulfur is essential as the analogous phosphoramide gave low yield and no selectivity. Additionally, both key moieties are located in close vicinity and inside the chiral pocket that is delineated by the large aromatic groups in the ortho positions of the binol backbone. 


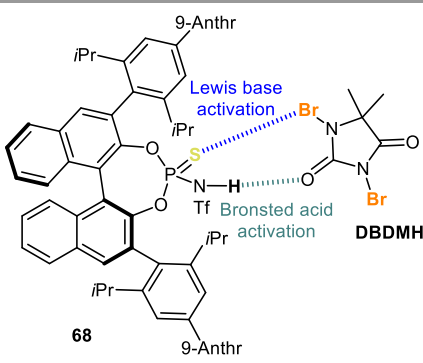

Figure 4 Activation of DBDMH by a thiophosphoramide

Using only 5 mol\% of catalyst $\mathbf{6 8}$ with DBDMH promoted the cyclization of homogeranylarenes 9 leading, after acidic treatment in most cases, to the brominated tricycles $\mathbf{1 0}$ with yields ranging from $44 \%$ to $98 \%$ and enantiomeric ratios up to 97:3 (Scheme 26).

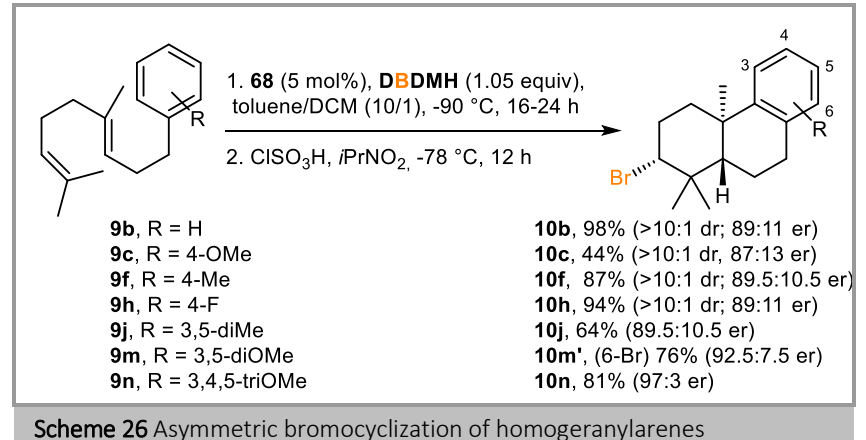

When the same reaction conditions were applied to geranylbenzene, a mixture of endo- and exo-monocyclized products 49a and 49a' were obtained in $82 \%$ combined yield and $84 \%$ ee for the former and only $26 \%$ ee for the latter (Scheme 27). In sharp contrast to what was observed by Ishihara with his phosphite-urea catalyst (Scheme 25), when applied to geranylphenols these conditions favor the formation of tricyclic products $\mathbf{5 0}$ with moderate to good yields and good enantiomeric excesses.

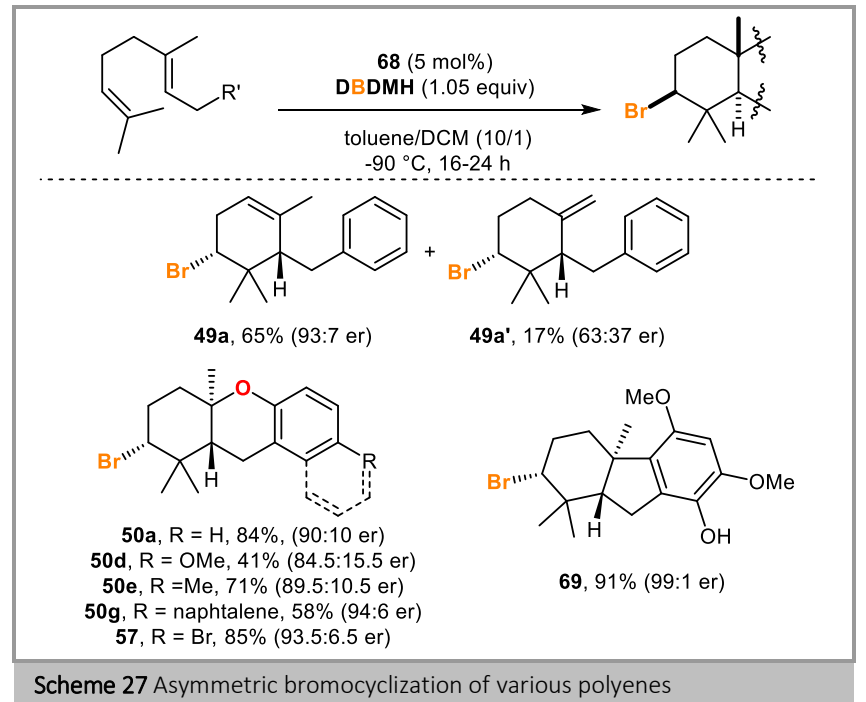

Moreover, for the substrate bearing a 2,4-dimethoxyphenol moiety, the intermediate carbocation was trapped by a C-C bond of the aromatic ring, yielding [6,5,6]-fused tricycle 69 rather than the corresponding oxygenated $[6,6,6]$-fused system.

\section{Total Synthesis of Halogenated Natural Products}

From the onset, the goal of the research on the halocyclization of polyenes was to mimic Nature in order to access structurally complex molecules. Thus, numerous efforts have been devoted to apply this strategy for the total synthesis of natural products incorporating halogen atoms. ${ }^{47}$

\subsection{Using NBS}

In 1977, the group of Gonzales started their synthesis of snyderol by cyclizing methyl farnesate 6 into diene 8 in 12\% yield using NBS with copper(II) acetate (Scheme 28).48 Reduction of the ester and bromination of the resulting allylic alcohol led to $\mathbf{7 0}$ that was then converted into snyderol by an aqueous acidic treatment.

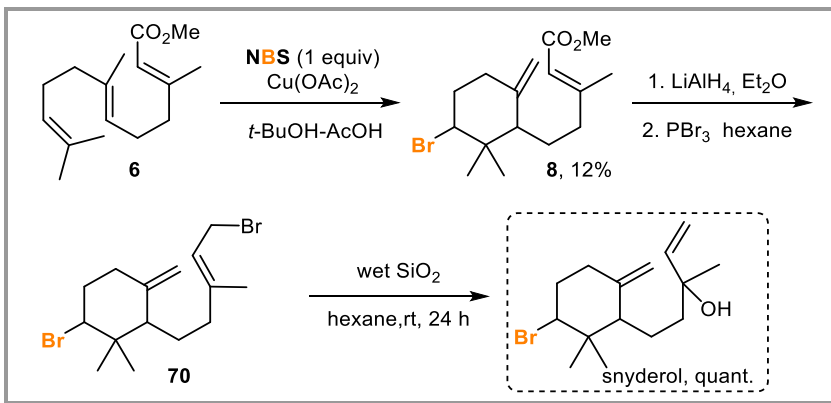

Scheme 28 First total synthesis of snyderol using NBS

In 2014, McErlean undertook the synthesis of luzofuran, isolated from the red alga Laurencia luzonensis. ${ }^{49}$ Phosphoramidite (S)-TCPT (56) was used to promote the bromocyclization of enantioenriched furanic alcohol $\mathbf{7 1}$ with NBS to directly access (+)-luzofuran (Scheme 29, eq.1). ${ }^{50}$ The latter was obtained alongside minor amount of its epimer $\mathbf{7 2}$, which could in turn be transformed into (-)-ancistrofuran (itself isolated from the defensive secretions of the West African termite Ancistrotermes cavithorax ${ }^{51}$ ) by debromination (Scheme 29, eq. 2).

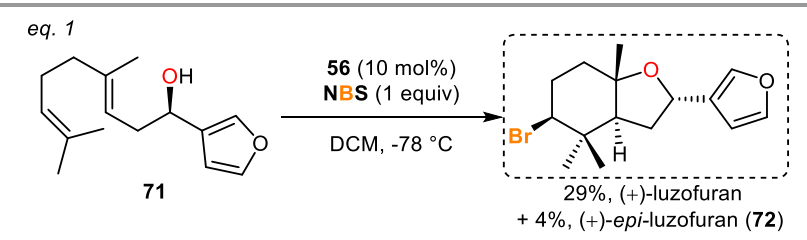

eq. 2

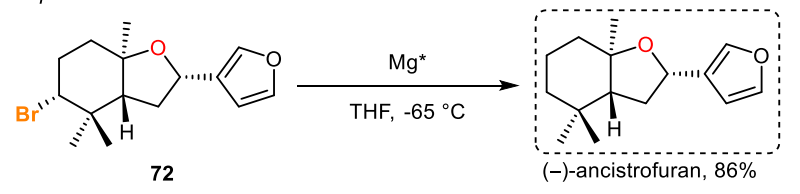

Scheme 29 First total synthesis of Snyderol using NBS

Although the target compounds were effectively obtained, both examples show the poor performance of NBS, even in the presence of a promoter, for bromo-carbocyclizations. 
<smiles>CC1=CCCC(C)=C1CC[C@H]1C(=O)OC[C@H]1O</smiles>

73

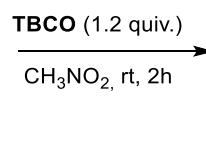

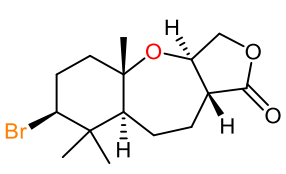

74, $2.4 \%$ (+ 9.6\% Br epimer)
1. LDA, $\mathrm{PhSeBr}, \mathrm{THF},-78^{\circ} \mathrm{C}$

2. $\mathrm{H}_{2} \mathrm{O}_{2}, \mathrm{AcOH}$ cat.THF, $0^{\circ} \mathrm{C}$

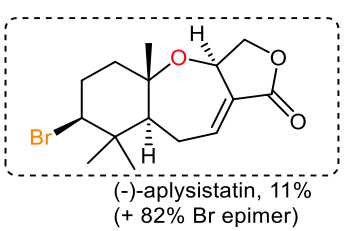

Scheme 30 Total synthesis of aplysistatin using TBCO for the key bromocyclization

Hence, many groups turned their attention towards specially designed reagents such as TBCO or BDSB to improve the efficiency of the key cyclization step.

\subsection{TBCO}

To synthetize (-)-aplysistatin, an antineoplastic isolated form the sea hare Aplysia angasi, ${ }^{52}$ Prestwich used TBCO as the promoter for the key bromocyclization. ${ }^{53}$ Cyclization of enantioenriched geranyl- $\gamma$-butyrolactone $\mathbf{7 3}$ with TBCO led to the desired tricycle $\mathbf{7 4}$ and its bromo-epimer in a combined $12 \%$ yield (Scheme 30). This mixture was then converted into (-)aplysistatin (and its bromo-epimer) by a selenation/oxidation/ elimination sequence in $93 \%$ yield. The pure natural product could be isolated from the epimer-mixture by HPLC. Although the yield of the cyclization is rather low and the desired diastereoisomer is the minor one formed, this route is, nevertheless, rather straightforward and avoids the use of stoichiometric amount of toxic mercury salt as previously reported by Hoye for the racemic synthesis of aplysistatin. ${ }^{54}$

A TBCO-promoted bromocyclization was used by the group of Kato as the key step for the total synthesis of a series of molecules. In 1985, they reported the synthesis of both concinndiol ${ }^{55}$ and aplysin $20^{56}$ from a common precursor (Scheme 31).57 Using acetonitrile as the solvent favored the cyclization of geranylgeranate $\mathbf{7 5}$ initiated by TBCO and gave brominated bicylic product 76 in 20\% yield (along with 30\% of the monocyclic product). Epoxidation of the endo-cyclic double bond led to a 2:1 mixture of isomers 77:78 (Scheme 31, eq. 1). 77 was selectively reduced with aluminum hydride to the corresponding allylic alcohol $\mathbf{7 9}$ which was converted into concinndiol in three steps (Scheme 31, eq. 2). Longer exposure to aluminum hydride of the other diastereoisomer $\mathbf{7 8}$ triggered the reduction of the ester and the opening of the oxirane to give aplysin-20 in one step (Scheme 31, eq. 3).

A slightly modified strategy was then used for the total synthesis of pinnatol $\mathrm{D}^{58}$ and isoconcinndiol..$^{59}$ Starting from farnesyl derivative 79, TBCO-promoted bromocyclization gave a complex mixture out of which the desired bicyclic product $\mathbf{8 0}$ could be isolated in $30 \%$ yield as a $1: 1$ mixture of isomers (Scheme 32, eq. 1).60 Both the benzoate and the methyl ester were reduced to furnish the two corresponding diastereoisomeric diols, that were separated by chromatography. From diastereoisomer 81, pinnatol D could then be attained by a Grieco elimination. From pinnatol D, epoxidation followed by reduction with aluminum hydride gave conncindiol. Alternatively, after protection of the diol, regio- and stereo-selective hydroboration of the endocyclic double bond followed by oxidation installed the tertiary alcohol of $\mathbf{8 2}$ (Scheme 32, eq. 2). Finally, a Grieco elimination was then performed to access isoconcinndiol. In order to access cyclocymopol, ${ }^{61}$ Tanaka used TBCO on dimethoxypheny-geranyl derivative $66 \mathbf{g}$, which led to the desired methylenebromocyclohexane $\mathbf{6 7 g}$ in $35 \%$ yield (Scheme 33). ${ }^{62}$ Removal of both methyl groups was carried out in a two-step sequence, starting with a silver-mediated oxidation into a benzoquinone that was reduced with sodium hydrosulfite to give cyclocymopol in $20 \%$ yield. The TBCO-promoted bromocyclization protocol was applied to the analogous di-MOM-protected geranyl derivative 38. ${ }^{63}$<smiles>CC1=CCCC2=C1CCC=C(CC(=O)OCC(C)(C)C)C2</smiles>

eq. 2

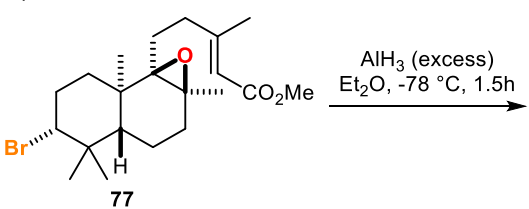

eq. 3

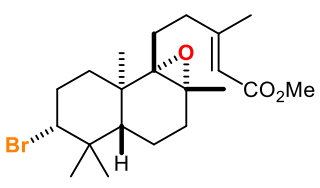

78

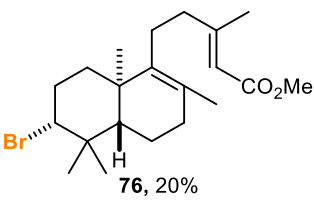

$m$ CPBA (1.2 equiv.) $\underset{\mathrm{CH}_{2} \mathrm{Cl}_{2} \text {, rt }}{\stackrel{\mathrm{NaHCO}_{3}(1.5 \text { equiv. })}{\longrightarrow}}$ 76, 20\%

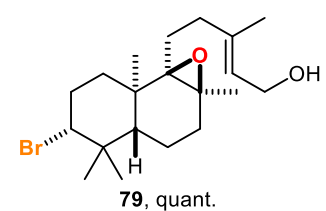
79 , quant.

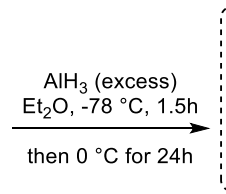

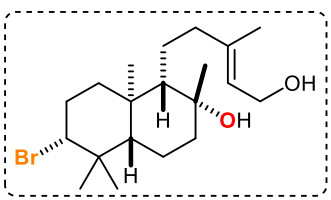

$( \pm)$ aplysin-20, 80\%

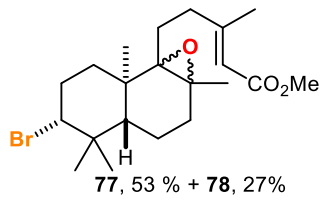

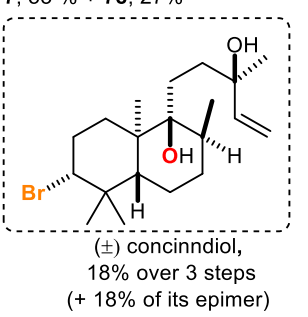

Scheme 31 Total synthesis of concinndiol and aplysin 20 using TBCO for the key bromocyclization 


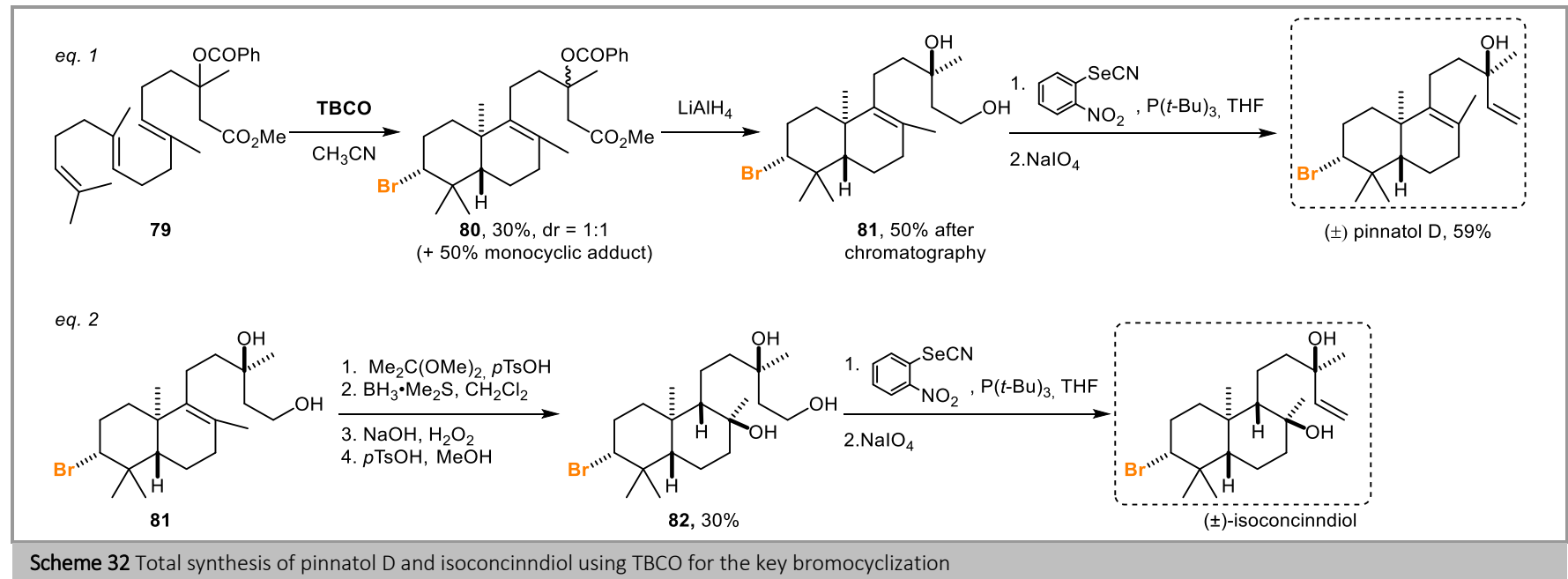

Scheme 32 Total synthesis of pinnatol D and isoconcinndiol using TBCO for the key bromocyclization

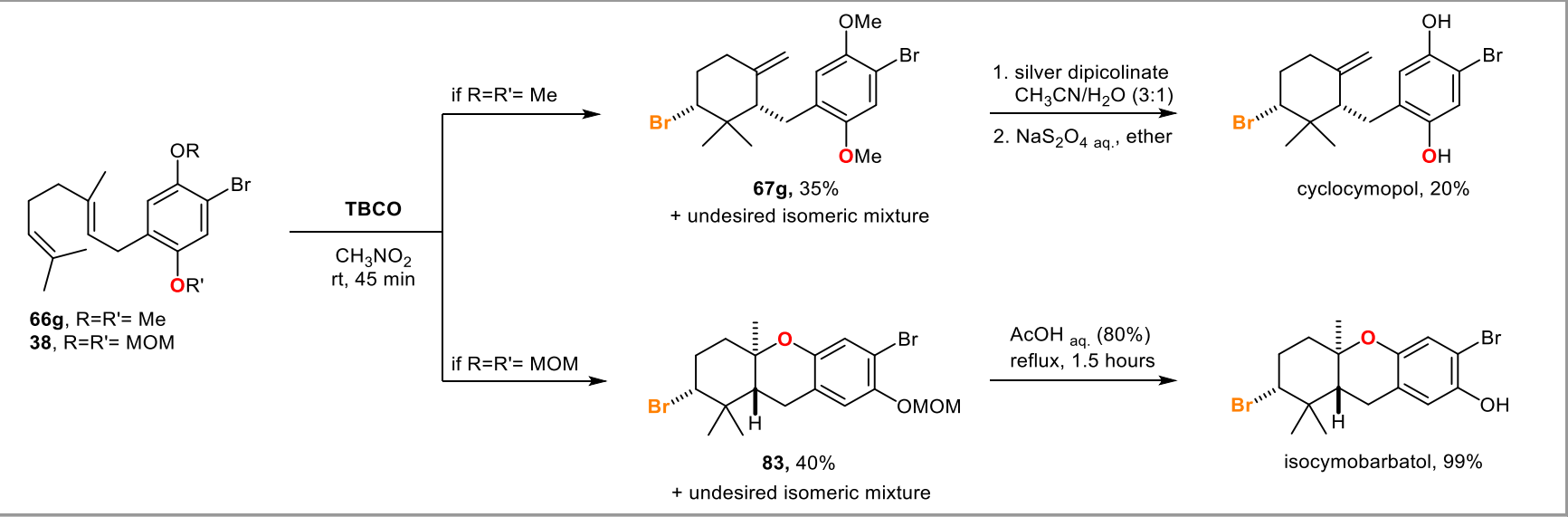

Scheme 33 Total synthesis of cyclocymopol and isocycmobarbatol using TBCO for the key bromocyclization

In this case, concomitantly with the loss of a MOM group, tricyclic product 83 was obtained in $40 \%$ yield. Acidic cleavage of the remaining protecting group led to isocycmobarbatol ${ }^{32}$ in near quantitative yield.

\subsection{BDSB}

The development of BDSB by Snyder opened promising perspectives for targeting brominated natural products as first exemplified by its use for the synthesis of isocymobarbatol. ${ }^{21}$ Compared to TBCO, BDSB proved to be far more efficient since the bromocyclization of compound $\mathbf{3 8}$ took place in only five minutes to give $\mathbf{8 3}$ with $74 \%$ yield (Scheme 34 ).

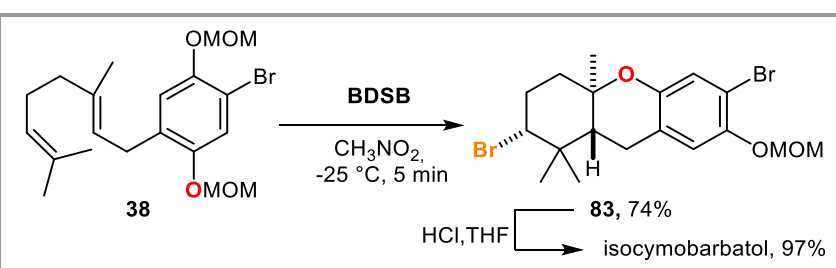

Scheme 34 Total synthesis of isocycmobarbatol using BDSB for the key bromocyclization

Shortly after, Snyder undertook the total synthesis of peyssonol A, ${ }^{64}$ whose relative configuration was unambiguously assigned by performing the same synthetic sequence starting from different trienes. ${ }^{23}$ The actual peyssonol A was obtained starting from triene $\mathbf{8 4}$ that was submitted to the action of BDSB to give tricyclic carbonate 85 in $56 \%$ yield (Scheme 34, eq. 1).
Methanolysis followed by oxidation of the primary alcohol and elimination of the tertiary alcohol led to decaline 86 in 76\% yield. The synthesis was completed by adding the aryl moiety as its lithium derivative followed by reduction of the benzylic alcohol, formylation and acidic cleavage of the MOM groups, furnishing peyssonol A in a $15 \%$ overall yield. In addition to the various isomers that were synthetized, a iodo-analogue was constructed using IDSI instead of BDSB and all the synthesized compounds were evaluated for their HIV-1 inhibition properties. ${ }^{65}$ To access peyssonoic acid A, ${ }^{66}$ a slightly different approach was chosen and the bromocyclization was performed on triene $\mathbf{8 7}$ that already incorporated the aryl moiety (Scheme 35 , eq. 2). This gave tetracycle 88 in $31 \%$ yield with a good chemoselectivity since the allyl group was untouched. The later was then fully oxidized to the carboxylic acid, then treatment with boron trichloride cleaved both ethers to deliver peyssonoic acid A. Snyder also disclosed the utility of BDSB to access various bromo-chamigrenes derivatives, albeit unnatural ones.67 Krauss, decided to use BDSB on macrocylic triene $\mathbf{8 9}$ to trigger a transannular bromocyclization, via bromiranium 90 , to access bromophycolides ${ }^{68}$ derivatives (Scheme 36). Macrocycle 89 was obtained as the $S$-enantiomer (ee 92\%) using a regiospecific Sharpless asymmetric dihydroxylation and a Shiina macrocyclization as the key steps. ${ }^{69}$ When submitted to BDSB in a highly polar media (addition of aqueous $1 \mathrm{M} \mathrm{LiClO}_{4}$ to the solvent) the major products obtained were allylic bromides 91 and 91'. 


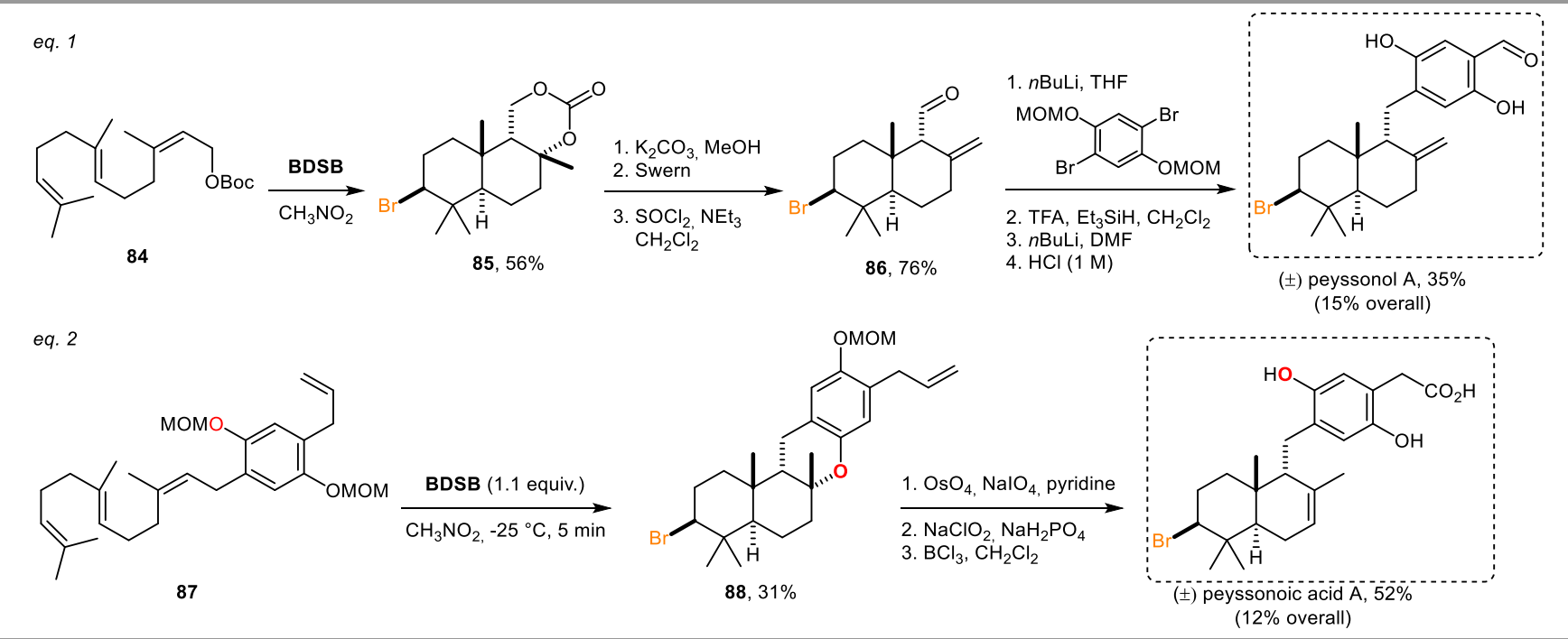

Scheme 35 Total synthesis of peyssonol A and peyssonoic acid A using BDSB for the key bromocyclization

Yet, ca 20\% of monocyclized compounds 92 and 93 were also obtained, the latter exhibiting a bromophycolides D skeleton with an exo-cyclic double bond.68a Unfortunately, the authors were unable to form the bromohydrin on the remaining double bond embedded in the macrocycle, which would have completed the total synthesis.

\section{Conclusion and Perspectives}

In more than fifty years after the initial report of a direct bromocyclization of a polyene by Van Tamelen, tremendous improvements have been achieved. The development of reagents such as BDSB allowed to increase yields by tenfold, thus making these transformations sufficiently efficient to tackle the synthesis of complex compounds, including polycyclic halogenated natural products. Additionally, following the seminal report by Ishihara in 2007, catalytic enantioselective versions have also been developed. Nevertheless, the vast majority of the literature on the topic deals with bromocyclizations whilst iodocyclization remains rare,chlorocyclization even more scarce, without mentioning the fact that a direct fluorocyclization of polyene has yet to be described. ${ }^{70}$ Therefore, future developments should aim to overcome these limitations.

\section{Funding Information}

CNRS, ICSN, Labex Lermit (ANR grant ANR-10-LABX-33 under the program Investissements D'Avenir ANR-11-IDEX-0003-01) and University Paris Saclay.

\section{Acknowledgment}

A. C. D. thanks Labex Lermit for a postdoctoral fellowship, L. P. thanks University Paris Saclay for a PhD fellowship and T. D. G. thanks ICSN for a PhD fellowship. Drs R. H. Dodd and J. Dubois (ICSN) are warmly thanked for their contribution to the group's research in this field.

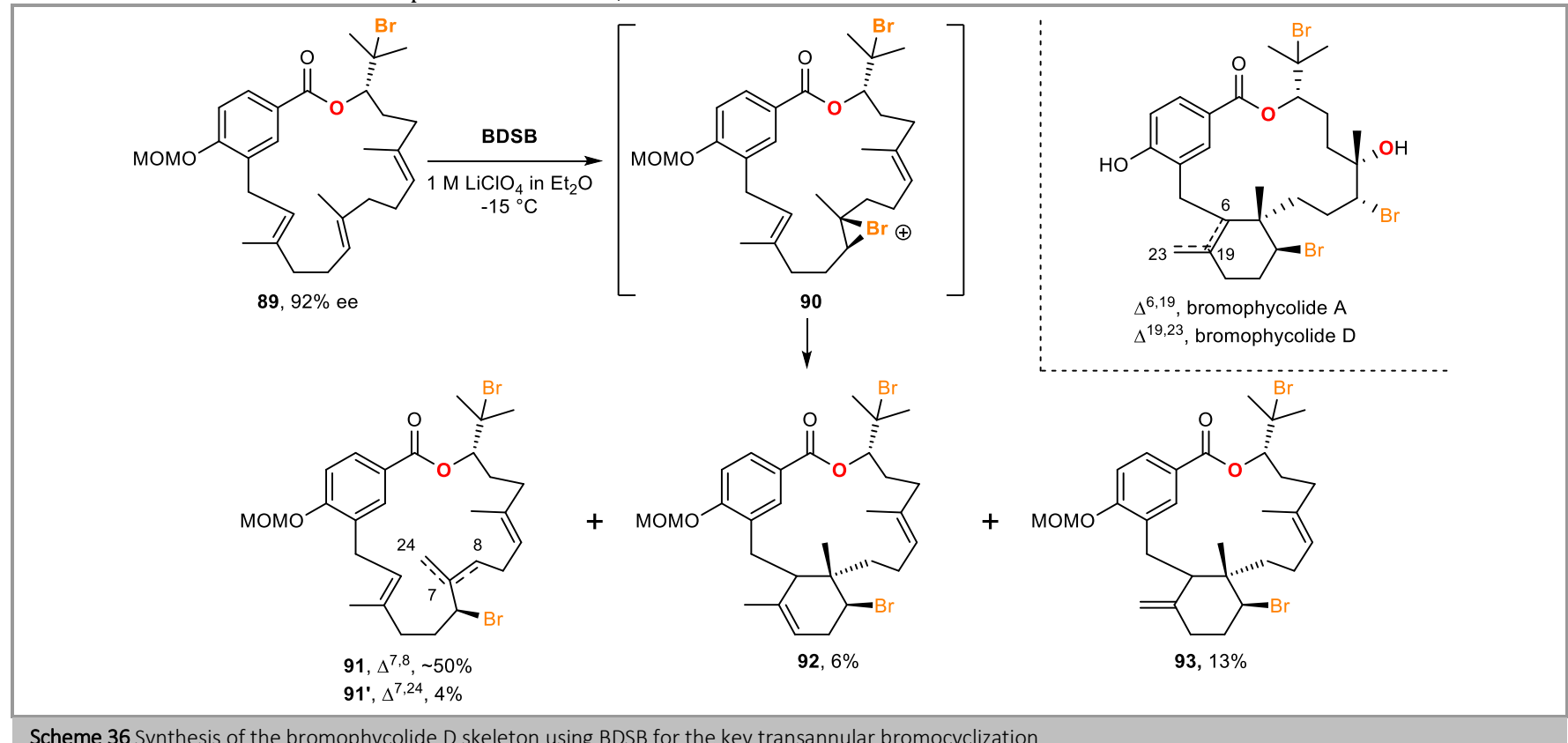

Scheme 36 Synthesis of the bromophycolide D skeleton using BDSB for the key transannular bromocyclization

\section{References}

(1) Stork, G.; Burgstahler, A. W. J. Am. Chem. Soc. 1955, 77, 5068
(2) (a) Eschenmoser, A.; Ruzicka, L.; Jeger, O.; Arigoni, D. Helv. Chim. Acta 1955, 38, 1890. (b) Eschenmoser, A.; Arigoni, D. Helv. Chim. Acta 2005, 88, 3011. 
(3) For key reviews on polyene cyclizations, see: (a) W. S. Johnson, Angew. Chem., Int. Ed. Engl. 1976, 15, 9. (b) Yoder, R. A.; Johnston, J. N. Chem. Rev. 2005, 105, 4730. (c) Snyder, S. A.; Levinson, A. M. In Compr. Org. Synth., 2nd ed.; Knochel, P., Molander, G. A., Eds.; Elsevier: Amsterdam, 2014; 3, 268. (d) Baunach, M.; Franke, J.; Hertweck, C. Angew. Chem., Int. Ed. 2015, 54, 2604. (e) Ungarean, C. N.; Southgate, E. H.; Sarlah, D. Org. Biomol. Chem. 2016, 14, 5454. (f) Barrett, A. G. M.; Ma, T.-K.; Mies T. Synthesis 2018, DOI: 10.1055/s-0037-1610382; Art ID: ss-2018-z0694-sr.

(4) (a) Faulkner, D. J. Tetrahedron 1977, 33, 1421. (b) Gribble, G. W.J. Nat. Prod. 1992, 55, 1353. (c) Wang, B.-G.; Gloer, J. B.; Ji, N.-Y.; Zhao, J.-C. Chem. Rev. 2013, 113, 3632.

(5) Gribble, G. W. J. Chem. Educ. 2004, 81, 1441.

(6) Chung, W.-J.; Vanderwal, C. D. Angew. Chem., Int. Ed. 2016, 55, 4396

(7) (a) Butler, A.; Carter-Franklin, J. N. Nat. Prod. Rep. 2004, 21, 180 (b) Vaillancourt, F. H.; Yeh, E.; Vosburg, D. A.; Garneau-Tsodikova, S.; Walsh, C. T. Chem. Rev. 2006, 106, 3364. (c) Butler, A.; Moriah S. Nature 2009, 460, 848. (d) Agarwal, V.; Miles, Z. D.; Winter, J. M.; Eustaquio, A. S.; El Gamal, A. A.; Moore, B. S. Chem. Rev. 2017, 117, 5619.

(8) Kubanek, J.; Prusak, A. C.; Snell, T. W.; Giese, R. A.; Hardcastle, K. I.; Fairchild, C. R.; Aalbersberg, W.; Raventos-Suarez, C.; Hay, M. E. Org. Lett. 2005, 7, 5261.

(9) (a) Braddock, D. C.; Marklew, J. S.; Foote, K. M.; White, A. J. P. Chirality 2013, 25, 692. (b) Burckle, A. J.; Gál, B.; Seidl, F. J.; Vasilev, V. H.; Burns, N. Z. J. Am. Chem. Soc. 2017, 139, 13562.

(10) For other reviews covering some of these aspects, see: Snyder, S. A.; Treitler, D. S.; Brucks, A. P. Aldrichimica Acta. 2011, 44, 27.

(11) Van Tamelen, E. E.; Hessler, E. J. Chem. Commun. 1966, 411.

(12) Nasipuri, D.; Ray Chaudhuri, S. R. J. Chem. Soc. Perkin Trans I 1975, 262. Nasipuri, D.; Ray Chaudhuri, S. R. J. Chem. Soc. Perkin Trans I 1975, 262.

(13) Wolinsky, L. E.; Faulkner, D. J. J. Org. Chem. 1976, 41, 597.

(14) Kato, T.; Ichinose, I.; Kumazawa, S.; Kitahara, Y. Bioorg. Chem. 1975 $4,188$.

(15) Kitahara, Y.; Kato, T.; Ichinose, I. Chem. Lett., 1976, 283.

(16) Kato, T.; Ichinose, I. J. Chem. Soc. Perkin Trans I 1980, 1051.

(17) Barluenga, J.; Gonza'lez, J. M.; Campos, P. J.; Asensio, G. Angew. Chem., Int. Ed. Engl. 1985, 24, 319.

(18) Barluenga, J.; Gonza'lez, J. M.; Campos, P. J.; Asensio, G. Angew. Chem., Int. Ed. Engl. 1988, 27, 1546.

(19) Günther, H. J.; Jäger, V.; Skell, P. S. Tetrahedron Lett. 1977, 18, 2539.

(20) Barluenga, J.; Trincado, M.; Rubio, E.; González, J. M. J. Am. Chem. Soc. 2004, 126, 3416.

(21) Snyder, S. A.; Treitler, D. S. Angew. Chem., Int. Ed. 2009, 48, 7899.

(22) Snyder, S. A.; Treitler, D. S. Org. Synth. 2011, 88, 54.

(23) Snyder, S. A.; Treitler, D. S.; Brucks, A. P. J. Am. Chem. Soc. 2010, 132, 14303.

(24) Marquet A.; Jacques. J. Tetrahedron Letters. 1959, 9,24.

(25) (a) Collado, I. G.; Madero, J. G.; Massanet, G. M.; Luis, F. R. Tetrahedron Lett. 1990, 31,563. (b) Collado, I. G.; Madero, J. G.; Massanet, G. M.; Luis, F. R. J. Org. Chem. 1991, 56, 3587.

(26) Jain, T. C.; Banke, C. M.; McCloekey, J. E. Tetrahedron 1979, 36, 886.

(27) (a) Butler, A.; Walker, J. V. Chem. Rev. 1993, 93, 1937. (b) Latham, J.; Brandenburger, E.; Shepherd, S. A.; Menon, B. R. K.; Micklefield, J. Chem. Rev. 2018, 118, 232.

(28) Carter-Franklin, J. N.; Parrish, J. D.; Tschirret-Guth, R. A.; Little, R. D.; Butler, A. J. Am. Chem. Soc. 2004, 126, 15060.

(29) Ascheberg, C.; Bock, J.; Buß, F.; Mück-Lichtenfeld, C.; Daniluc, C. G.; Bergander, K.; Dielmann, F.; Hennecke, U. Chem. - Eur. J. 2017, 23, 11578.

(30) Yoshimura, A.; Zhdankin, V. V. Chem. Rev. 2016, 116, 3328

(31) Grayfer, T. D.; Retailleau, P.; Dodd, R. H.; Dubois, J.; Cariou, K. Org. Lett. 2017, 19, 4766.

(32) Wall, M. E.; Wani, M. C.; Manikumar, G.; Taylor, H.; Hughes, T. J.; Gaetano, K.; Gerwick, W. H.; McPhail, A. T.; McPhail, D. R. J. Nat. Prod. 1989, 52, 1092

(33) Peilleron, L.; Grayfer, T. D.; Dubois, J.; Dodd, R. H.; Cariou, K. Beilstein J. Org. Chem. 2018, 14, 1103.
(34) Sakakura, A.; Ukai, A.; Ishihara, K. Nature 2007, 445, 900.

(35) Sawamura, Y.; Nakatsuji, H.; Sakakura, A.; Ishihara, K. Chem. Sci. 2013, 4, 4181.

(36) Sawamura, Y.; Nakatsuji, H.; Akakura, M.; Sakakura, A.; Ishihara, K. Chirality 2014, 26, 356.

(37) Recsei, C.; McErlean, C. S. P. Aust. J. Chem. 2015, 68, 555.

(38) Samanta, R. C.; Yamamoto H. Chem. Eur. J. 2015, 21, 11976

(39) Arnold, A. M.; Pöthig, A.; Drees, M.; Gulder, T.J. Am. Chem. Soc. 2018 140,4344

(40) For general reviews on enantioselective polyene cyclisation, see ref $3 e$.

(41) For recent general reviews on this topic, see: (a) Denmark, S. E.; Kuester, W. E.; Burk, M. T. Angew. Chem., Int. Ed. 2012, 51, 10938. (b) Mendoza, A.; Fananas, F. J.; Rodriguez, F. Curr. Org. Synth. 2013, 10, 384. (c) Tan, C. K.; Yeung, Y. Y. Chem. Commun. 2013, 49, 7985. (d) Cheng, Y. A.; Yu, W. Z.; Yeung, Y.-Y. Org. Biomol. Chem. 2014, 12, 2333. (e) Chen, J.; Zhou, L. Synthesis 2014, 46, 586. (f) Wolstenhulme, J. R.; Gouverneur, V. Acc. Chem. Res. 2014, 47, 3560; (g) Tan, C. K.;Yu,W. Z.;Yeung, Y.Y. Chirality 2014, 26, 328. (i) Zheng, S. Q.; Schienebeck, C. M.; Zhang, W.; Wang, H. Y.; Tang, W. P. Asian J. Org. Chem. 2014, 3, 366. (j) Cresswell, A. J.; Eey, S. T. C.; Denmark, S. E. Angew. Chem., Int. Ed. 2015, 54, 15642.

(42) For a highlight specifically on this topic, see: Chen, G.; Ma, S. Angew. Chem. Int. Ed. 2010, 49, 8306

(43) For key reviews specifically on this topic, see: (a) Cresswell, A. J.; Eey, S. T.-C.; Denmark, S. E. Angew. Chem., Int. Ed. 2015, 54, 15642. (b) Landry, M. L.; Burns, N. Z. Acc. Chem. Res. 2018, 51, 1260.

(44) Sakakura, A.; Ishihara, K. Chem. Rec. 2015, 15, 728.

(45) Sawamura, Y.; Ogura, Y.; Nakatsuji, H.; Sakakura, A.; Ishihara, K. Chem. Commun. 2016, 52, 6068.

(46) Samanta, R. C.; Yamamoto H. J. Am. Chem. Soc. 2017, 139, 1460.

(47) For seminal and recent reviews covering some aspects of this section, see: (a) Faulkner, D. J. Pure Appl. Chem. 1976, 48, 25. (b) Ardkhean, R.; Caputo, D. F. J.; Morrow, S. M.; Shi, H.; Xiong, Y.; Anderson, E. A. Chem. Soc. Rev. 2016, 45, 1557 and references $3 f$ \& 6.

(48) González, A. G.; Martin, J. D.; Pérez, C.; Ramirez, M. A. Tetrahedron Lett. 1976, 17, 137

(49) Kuniyoshi, M.; Wahome, P. G.; Miono, T.; Hashimoto, T.; Yokoyama, M.; Shrestha, K. L.; Higa, T. J. Nat. Prod. 2005, 68, 1314.

(50) Recsei, C.; Chan, B.; McErlean, C. S. P. J. Org. Chem. 2014, 79, 880.

(51) Baker, R.; Briner, P. H.; Evans, D. A. J. Chem. Soc., Chem. Commun 1978, 410

(52) Pettit, G.R.; Herald, C.L; Allen, M.S.; Von Dreele, R.B.; Vanell, L.D.; Kao, J.P.Y.; Blake, W., J. Am. Chem. Soc., 1977, 99, 262.

(53) Shieh, H.-M.; Prestwich, G. D. Tetrahedron Lett. 1982, 23, 4643.

(54) Hoye, T. R.; Kurth M. J., J. Am. Chem. Soc., 1979, 101, 5065-5067. Hoye, T. R.; Caruso, A. J.; Dellarla, F. F. and Kurth, M. J. J. Am. Chem. Soc., 1982, 104, 6704.

(55) Sims, J. J.; Lin, G. H. Y.; Wing, R. M.; Fenical, W. Chem. Commun. 1973 470.

(56) Yamamura Y.; Hirata, Y. Bull. Chem. Sot. Jpn. 1971, 44, 2560.

(57) Yamaguchi, Y.; Uyehara, T.; Kato, T. Tetrahedron Lett. 1985, 26, 343.

(58) Fukuzawa, A.; Miyamoto, M.; Kumagai, Y.; Abiko, A.; Takaya, Y.; Masamune, T. Chem. Lett. 1985, 1259

(59) Howard, B.M.; Fenical, W. Phytochemistry 1980, 19, 2774

(60) Fujiwara, S.; Takeda, K.; Uyehara, K.; Kato, T. Chem. Lett. 1986, 1763.

(61) (a) Hogberg, H.-E.; Thomson R. H.; King, T. J. J. Chem. Soc., Perkin Trans. 1 1976, 1696. (b) McConnel, O. J.; Hughes, P. A.; Targett, N. M. Phytochemistry 1982, 21, 2139.

(62) Tanaka, A.; Sato, M.; Yamashita, K. Agric. Biol. Chem. 1990, 54, 121.

(63) Tanaka, A.; Oritani, T. Biosci., Biotechnol., Biochem. 1995, 59, 516.

(64) (a) Talpir, R.; Rudi, A.; Kashman, Y.; Loya, Y.; Hizi, A. Tetrahedron 1994, 50, 4179. (b) Loya, S.; Bakhanaskvili, M.; Kashman, Y.; Hizi, A. Arch. Biochem. Biophys. 1995, 316, 789.

(65) Treitler, D.S.; Li, Z.; Krystal, M.; Meanwell, N.A.; Snyder, S.A. Bioorg. Med. Chem. Lett. 2013, 23, 2192. 
(66) Lane, A. L.; Mular, L.; Drenkard, E. J.; Shearer, T. L.; Engel, S.; Fredericq, S.; Fairchild, C. R.; Prudhomme, J.; Le Roch, K.; Hay, M. E.; Aalbersberg, W.; Kubanek, J. Tetrahedron 2010, 66, 455.

(67) Shen, M.; Kretschmer, M.; Brill, Z. G.; Snyder, S. A. Org. Lett. 2016, $18,5018$.

(68) (a) Kubanek, J.; Prusak, A. C.; Snell, T. W.; Giese, R. A.; Fairchild, C. R.; Aalbersberg, W.; Hay, M. H. J. Nat. Prod. 2006, 69, 731. (b) Lane, A. L.; Stout, E. P.; Lin, A.-S.; Prudhomme, J.; Le Roch, K.; Fairchild, C. R.; Franzblau, S. G.; Hay, M. E.; Aalbersberg, W.; Kubanek, J. J. Org.
Chem. 2009, 74, 2736. (c) Lin, A. S.; Stout, E. P.; Prudhomme, J.; Le Roch, K.; Fairchild, C. R.; Franzblau, S. G.; Aalbersberg, W.; Hay, M. E.; Kubanek, J. J. Nat. Prod. 2010, 73, 275 and reference 8.

(69) Lin, H.; Pochapsky, S. S.; Krauss, I. J. Org. Lett. 2011, 13, 1222.

(70) Gagné proposed an elegant solution by the mean of an enantioselective $\mathrm{Pt}(\mathrm{II})$-catalyzed cyclization of polyene that is terminated by a fluoro-demetallation with $\mathrm{XeF}_{2}$, see: Cochrane, $\mathrm{N}$. A.; Nguyen, H.; Gagné, M. R. J. Am. Chem. Soc. 2013, 135, 628. 


\section{Biosketches}

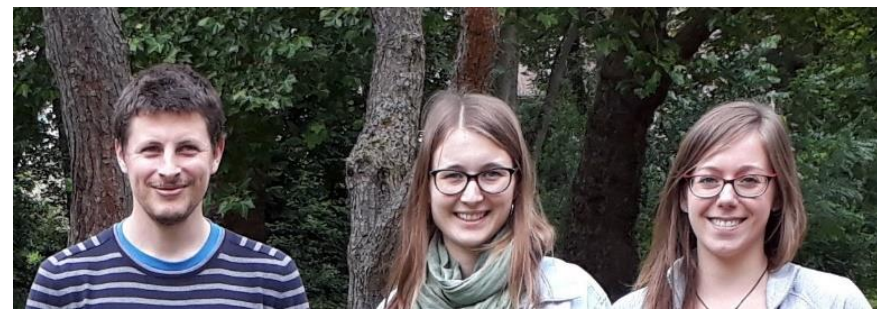

Kevin Cariou (left) after graduating from ChimieParisTech in 2002, he received his PhD in 2006 from the University Pierre and Marie Curie (now Sorbonne University) in Paris (France) under the supervision of Prof. M. Malacria and L. Fensterbank, where he studied platinum- and gold-catalyzed transformations with a joint CNRS-Sanofi BDI fellowship. From 2007 to 2009, including one-year as a Lavoisier fellowship holder, he worked as a postdoctoral researcher in the group of Prof. A. J. Frontier at the University of Rochester (NY, USA) in the field of total synthesis. He was appointed a Chargé de Recherche in 2009 at the CNRS at the ICSN in the team Synthesis and Methodology Applied to Research in Therapeutics (SMART) led by Dr R. H. Dodd. Since 2017, he has become the leader of the SMART team and his current research interest lie in the development of new synthetic methods, with a focus on iodine(III) reagents and nitrogen-rich building blocks, and their application toward the synthesis of biologically active molecules.

Agathe D'Hollander (right) was born and raised in the North of France near Dunkerque and graduated (head of class) from the Ecole Nationale Supérieure de Chimie de Lille in 2013. She obtained her PhD in 2017 from the University of St Andrews (Scotland) under the joint supervision of Prof. N. J. Westwood (St Andrews), Prof. A.M. Thompson (Ninewells Hospital, Dundee, Scotland) and Prof. Sir D. P. Lane (A*STAR, Singapore) working on upregulators of the WTp53 protein. She joined the SMART team at the ICSN in 2017 to work on the development of carbapenemases inhibitors.

Laure Peilleron (middle) was born and raised in Orléans, France. She obtained a Master's degree in organic chemistry in 2016 from both ChimieParisTech and Sorbonne University. She started her PhD studies in October 2016 at the ICSN, under the direction of Dr. Kevin Cariou to work on hypervalent iodine(III) mediated halogenation reactions. 